\title{
MicroRNA-mRNA expression profiles and their potential role in cadmium stress response in Brassica napus
}

Ying $\mathrm{Fu}^{1}$, Annaliese S. Mason ${ }^{2}$, Yaofeng Zhang ${ }^{1}$, Baogang Lin ${ }^{1}$, Meili Xiao ${ }^{3}$, Donghui $\mathrm{Fu}^{3^{*}}$ and Huasheng Yu ${ }^{1 *}$

\begin{abstract}
Background: Oilseed rape is an excellent candidate for phytoremediation of cadmium (Cd) contaminated soils given its advantages of high biomass, fast growth, moderate metal accumulation, ease of harvesting, and metal tolerance, but the cadmium response pathways in this species (Brassica napus) have yet to be fully elucidated. A combined analysis of miRNA and mRNA expression to infer $C d$-induced regulation has not been reported in $B$. napus.
\end{abstract}

Results: We characterized concurrent changes in miRNA and mRNA profiles in the roots and shoots of $B$. napus seedlings after 10 days of $10 \mathrm{mg} / \mathrm{L} \mathrm{Cd}^{2+}$ treatment. Cd treatment significantly affected the expression of 22 miRNAs belonging to 11 families in the root and 29 miRNAs belonging to 14 miRNA families in the shoot. Five miRNA families (MIR395, MIR397, MIR398, MIR408 and MIR858) and three novel miRNAs were differentially expressed in both tissues. A total of 399 differentially expressed genes (DEGs) in the root and 389 DEGs in the shoot were identified, with very little overlap between tissue types. Eight anti-regulation miRNA-mRNA interaction pairs in the root and eight in the shoot were identified in response to $\mathrm{Cd}$ and were involved in key plant stress response pathways: for example, four genes targeted by miR398 were involved in a pathway for detoxification of superoxide radicals. Cd stress significantly impacted the photosynthetic pathway. Transcription factor activation, antioxidant response pathways and secondary metabolic processes such as glutathione (GSH) and phenylpropanoid metabolism were identified as major components for Cd-induced response in both roots and shoots.

Conclusions: Combined miRNA and mRNA profiling revealed miRNAs, genes and pathways involved in $\mathrm{Cd}$ response which are potentially critical for adaptation to $C d$ stress in $B$. napus. Close crosstalk between several $\mathrm{Cd}$-induced miRNAs and mRNAs was identified, shedding light on possible mechanisms for response to $\mathrm{Cd}$ stress in underground and aboveground tissues in B. napus. The pathways, genes, and miRNAs identified here will be valuable targets for future improvement of cadmium tolerance in B. napus.

Keywords: Brassica napus, Cadmium, microRNAs, mRNAs, Expression

\footnotetext{
*Correspondence: fudhui@163.com; yuhuasheng-0@163.com

${ }^{3}$ Key Laboratory of Crop Physiology, Ecology and Genetic Breeding, Ministry of Education, Agronomy College, Jiangxi Agricultural University, Nanchang 330045, China

${ }^{1}$ Institute of Crop and Nuclear Technology Utilization, Zhejiang Academy of

Agricultural Sciences, Hangzhou, China

Full list of author information is available at the end of the article
}

(c) The Author(s). 2019 Open Access This article is distributed under the terms of the Creative Commons Attribution 4.0 International License (http://creativecommons.org/licenses/by/4.0/), which permits unrestricted use, distribution, and reproduction in any medium, provided you give appropriate credit to the original author(s) and the source, provide a link to the Creative Commons license, and indicate if changes were made. The Creative Commons Public Domain Dedication waiver (http://creativecommons.org/publicdomain/zero/1.0/) applies to the data made available in this article, unless otherwise stated. 


\section{Background}

Cadmium (Cd) is one of the most serious major soil contaminants [1]. Cd is not an essential element for plants, but it can be readily absorbed by roots and transported to the above-ground organs [2]. Forty $\mathrm{mg} / \mathrm{L} \mathrm{Cd}$ in soil was already found to affect yield in some crops, while $200 \mathrm{mg} / \mathrm{L}$ had serious effects [3]. High Cd concentrations damage plant growth and reproduction through decreasing nutrient uptake, inhibiting photosynthetic activity [4], distorting membranes [5], and stunting plant growth [6], resulting in overall decreases in crop yield [2]. Cd accumulation in the human body over time poses serious health risks, including a risk of chronic toxicity in kidney tubules, bones, lungs and other organs [7].

Plants have evolved a range of mechanisms for heavy metal detoxification, including pumping heavy metals out of the plasma membrane, chelation, and binding to various thiol compounds in the cytosol followed by sequestration into vacuoles [8-10]. Antioxidant and signaling mechanisms also participate in the heavy metal detoxification process [11]. Glutathione $(\mathrm{GSH})$ is a well documented and also highly essential component for $\mathrm{Cd}$ detoxification [12], and GSH- or phytochelatin (PC)-conjugated vacuolar sequestration is one of the most important mechanisms of $\mathrm{Cd}$ accumulation and tolerance in plants [13-15]. Many other key genes have also been also shown to be involved in $\mathrm{Cd}$ detoxification and tolerance in plants, such as ZNT [16], HMA [14], NRAMP [14], ZntA [17], CAD [18], PDR [19, 20], PDR [20], ATM [21], ACBP [22], EIN [23], ABCC [14], ZIF [14], MTP [14], PCR [14], and $M A N$ [14]. Additionally, miRNAs play important roles in abiotic stress responses [24]. Cd-responsive miRNAs have been identified in rice (Oryza spp.) [25, 26], narrowleaf cattail (Typha angustifolia) [27], Medicago truncatula [28], and radish (Raphanus spp.) [29], strongly supporting miRNAs as key post-transcriptional regulators of $\mathrm{Cd}$ stress responses in plants [30].

Phytoremediation, where plants are used to remove heavy metals from soils, is an environmentally friendly, cost-effective technique for remediation of heavy metalcontaminated soils [31]. Oilseed rape (Brassica napus) is not only an important oil crop worldwide, but also an excellent candidate for phytoremediation given its advantages of high biomass, fast growth, moderate metal accumulation, ease of harvesting, and metal tolerance [32]. A number of studies have elucidated the physiological responses of $B$. napus to Cd stress, with identification of key Cd-stress-responsive genes BnPCS1, BnGSTU12, BnGSTU5, and BnHMAs. Three major studies to date have attempted to identify $C d$-responsive miRNAs through genome-wide studies in B. napus [3335]. Huang et al. (2010) found 58 miRNAs after small
RNA sequencing of root, stem and leaf tissue after treatment with $80 \mu \mathrm{M} \mathrm{Cd}$ (about $15 \mathrm{mg} / \mathrm{L}$ ) for 12, 24, 48 and $72 \mathrm{~h}$, of which 9 miRNAs were differentially expressed as a result of $\mathrm{Cd}$ stress in at least one tissue type relative to the control [33]. Zhou et al. (2012) found 84 miRNAs in root and shoot tissue of young seedlings after 40 and $80 \mu \mathrm{M} \mathrm{Cd}$ treatment for $6-48 \mathrm{~h}$, of which 13 miRNA families and five novel miRNAs were differentially expressed in the shoot and 8 miRNA families were differentially expressed in the root; at least 43 highconfidence gene targets of differentially expressed miRNAs in the roots and 126 convincing gene targets in the shoots were identified through degradome analysis [35]. Jian et al. (2018) looked at miRNA and mRNA expression in response to $1000 \mu \mathrm{M} \mathrm{CdCl} \mathrm{Cl}_{2}$ treatment (approximately $180 \mathrm{mg} / \mathrm{L}$ ) in whole $B$. napus seedlings 0,1 and 3 days after treatment, and identified 147 miRNAs, of which 39 were differentially expressed in response to $\mathrm{Cd}$ treatment, but for which target genes were only computationally predicted from the reference genome [34].

To date, studies have rarely profiled genome-wide miRNA and mRNA (gene expression) simultaneously under $\mathrm{Cd}$ stress. The optimal $\mathrm{Cd}$ concentration and treatment time with which to assess stress response is also still unclear. To acquire a deeper understanding of how miRNA might interact with mRNA to regulate response to $\mathrm{Cd}$ stress in $B$. napus, we sequenced miRNA and mRNA in root and shoot tissues of oilseed rape seedlings after an optimized Cd-stress treatment of 10 days at $10 \mathrm{mg} / \mathrm{L}$ and in controls, in order to help elucidate the molecular genetic mechanisms underlying oilseed rape response to $\mathrm{Cd}$ stress.

\section{Results}

Leaf chlorophyll content decreases in response to $\mathrm{cd}$ stress in B. napus

Leaf chlorophyll content clearly indicated response to Cd stress (Fig. 1a). Across all Cd treatment concentrations leaf chlorophyll content generally decreased until about day 10, then started to increase again (Fig. 1b). Of the different $\mathrm{Cd}$ treatments, $10 \mathrm{mg} / \mathrm{L} \mathrm{Cd}^{2+}$ for 10 days resulted in the maximum decrease in chlorophyll content. Thus, the seedlings treated with $10 \mathrm{mg} / \mathrm{L} \mathrm{Cd}^{2+}$ for 10 days were used for analysis of miRNA and mRNA expression profiles in response to $\mathrm{Cd}$ stress.

\section{Expression changes of miRNAs are involved in the response to $\mathrm{cd}$ in oilseed rape}

We constructed 12 small RNA libraries (root control, root $\mathrm{Cd}$ treatment, shoot control, shoot Cd treatment; three biological replicates for each sample), which yielded $284 \mathrm{M}$ raw reads, resulting in $239 \mathrm{M}$ clean reads (Additional file 1: Table S2). A total of 171 miRNAs were identified. The length distribution of miRNAs 

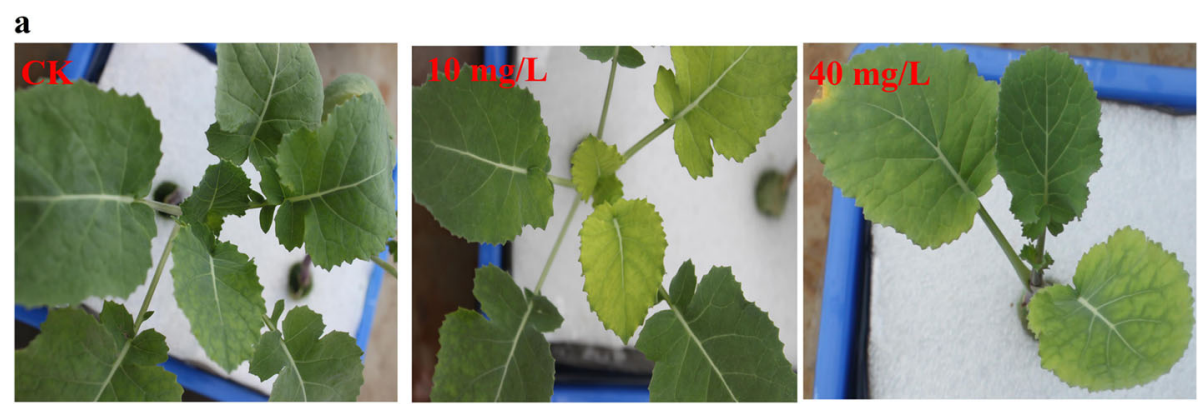

b
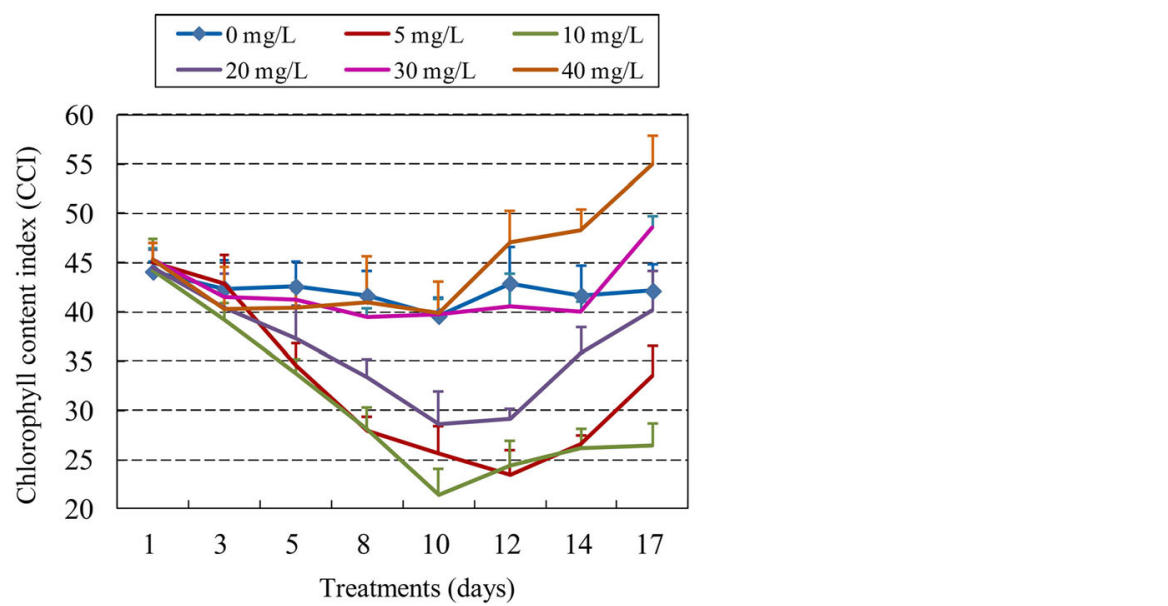

Fig. 1 The growth performance and total chlorophyll content changes of $B$. napus seedlings exposed to six Cd concentration gradients. a The leaf chlorosis performance of $B$. napus seedlings exposed to no stress and to $\mathrm{Cd}$ stress under different $\mathrm{Cd}$ concentrations. $\mathbf{b}$ The changes in total chlorophyll content of $B$. napus seedlings exposed to six $\mathrm{Cd}^{2+}$ concentrations over time: $0 \mathrm{mg} / \mathrm{L}$ (control), $5 \mathrm{mg} / \mathrm{L}, 10 \mathrm{mg} / \mathrm{L}, 20 \mathrm{mg} / \mathrm{L}$,

$30 \mathrm{mg} / \mathrm{L}, 40 \mathrm{mg} / \mathrm{L}$

ranged from $18 \mathrm{nt}$ to $25 \mathrm{nt}$ in the 12 small RNA libraries, of which the most abundant were $21 \mathrm{nt}$ miRNAs, followed by $24 \mathrm{nt}$ and $22 \mathrm{nt}$ miRNAs (Fig. 2a). Mature 20-22 nt miRNAs mostly started with ' $U$ ' as the first base $(62.2-100 \%)$, while 24 nt miRNAs mostly started with 'A' (75.8\%) (Fig. 2b). Of the 171 miRNAs identified, 99 (57.9\%) were previously known and belonged to 44 families. The 72 newly-predicted miRNAs are displayed in Additional file 1: Table S3.

Of the 171 miRNAs, 22 miRNAs in the root and 29 miRNAs in the shoot (20\%) were identified as differentially expressed under $\mathrm{Cd}$ stress relative to the control (Fig. 3a). Of these differentially expressed miRNAs, ten (seven previously known and three novel) were differentially expressed in both the root and shoot (Fig. 3b), with eight out of ten miRNAs showing up-regulation under $\mathrm{Cd}$ stress in both tissues. Expression trends for these miRNAs are shown in Fig. 3c: most differentially expressed miRNAs were upregulated after $\mathrm{Cd}$ treatment in the shoot, while the upand down-regulated miRNAs showed no significant difference in expression in the root after $\mathrm{Cd}$ treatment.

A total of 20 miRNA families were identified in these differentially expressed miRNAs, including 11 families differentially expressed in the root (13 miRNAs) and 14 families differentially expressed in the shoot $(20 \mathrm{miR}$ NAs) (Table 1). Of these, five families (MIR395, MIR397, MIR398, MIR408 and MIR858) and three novel miRNAs were differentially expressed in both tissues. All were up-regulated except for one down-regulated miRNA. These miRNAs also displayed the most significant expression changes in response to $\mathrm{Cd}$. The remaining six miRNA families were differentially expressed only in the root (one family up-regulated and five families down-regulated), while nine miRNA families were differentially expressed only in the shoot (five families up-regulated, three families down-regulated, and one miRNA family with both up- and down- regulated miRNAs).

\section{Changes in gene transcript levels are involved in the response to $\mathrm{cd}$ in oilseed rape}

A total of 44-64 $\mathrm{M}$ clean reads were generated from the mRNA expression profiles of 12 mRNA RNA libraries, with $61-70 \%$ of reads mapping to the reference genome (Additional file 1: Table S4). In all, 103,816 unigenes consisting of 2776 new genes and 101,040 reference genes were obtained, of which $98.6 \%$ (102392) could be annotated. 

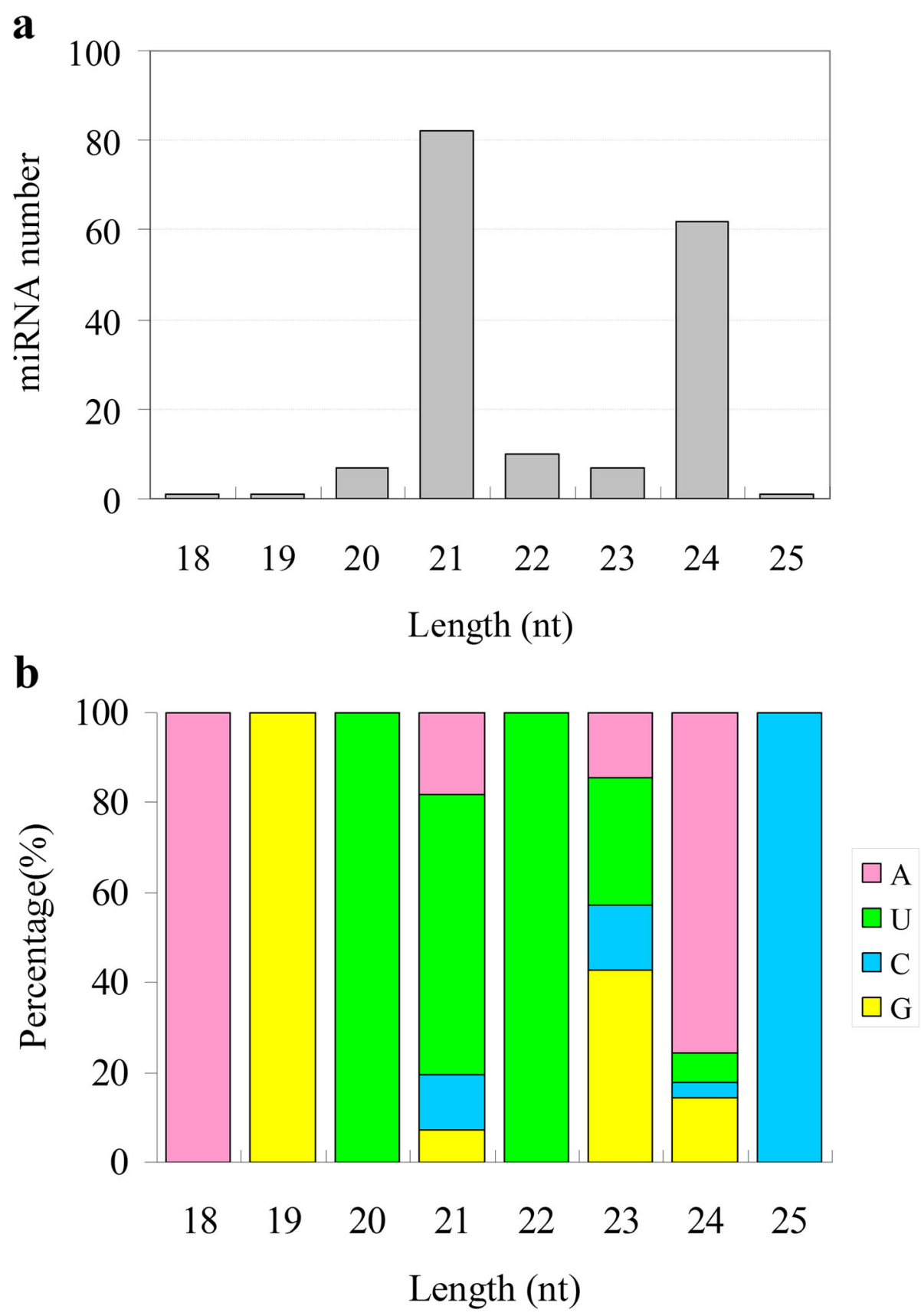

Fig. 2 Lengths of small RNAs (sRNAs) and first base s of mature miRNAs in 12 libraries (three biological replicates) constructed from shoot and root tissues of Brassica napus seedlings under 0 or $10 \mathrm{mg} / \mathrm{mL}$ cadmium stress for 10 days. a The proportion of sRNAs of different lengths in the 12 sequencing libraries. The Y-axis displays the number of sRNAs of a certain length, while the X-axis represents sRNAs of different lengths. $\mathbf{b}$ The first base preference of mature miRNAs in the 12 libraries. The Y-axis displays the proportion of mature miRNAs with a certain base type as the first base, and the $\mathrm{X}$-axis represents the length classification of the sRNAs

Overall, 103 up-regulated and 296 down-regulated genes in the root, 148 up-regulated and 241 downregulated genes in the shoot under $\mathrm{Cd}$ treatment were identified upon Cd treatment (Fig. 4a), of which eight genes were differentially expressed in both root and shoot tissues (Fig. 4b). Except for one differentially expressed gene (DEG) which was up-regulated in the shoot but down-regulated in the root, the remaining seven DEGs showed the same expression patterns in both root and shoot, with six genes up-regulated and one gene down-regulated. Expression patterns of these mRNAs are shown in Fig. 4c: most differentially 
a

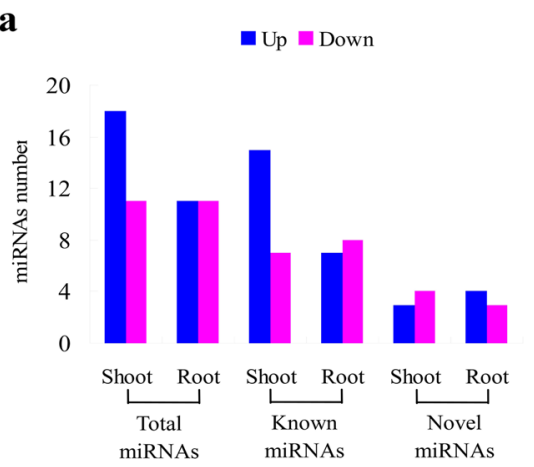

c

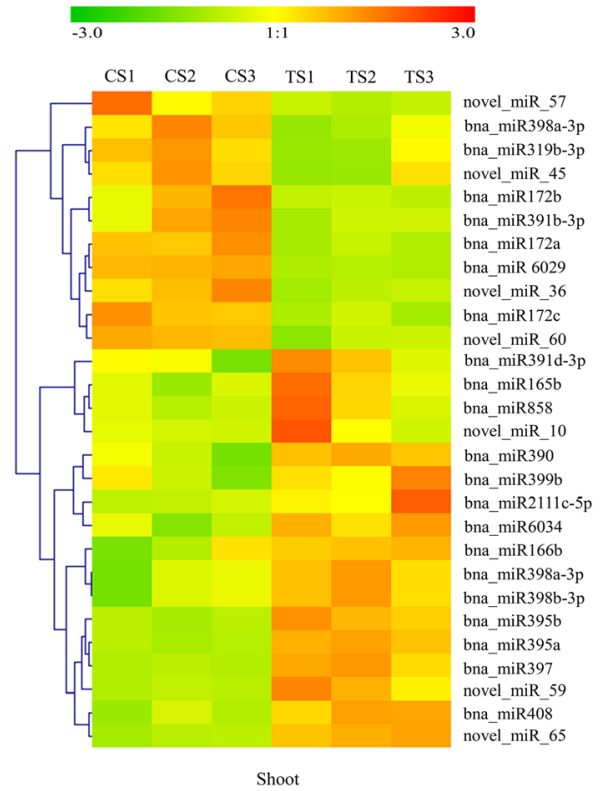

b
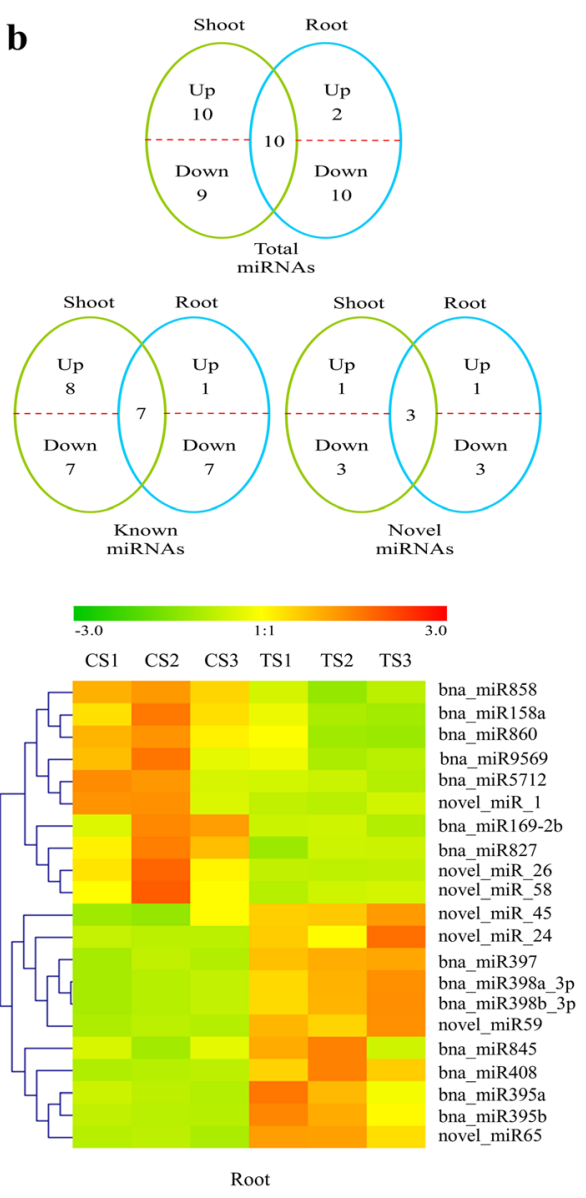

Fig. 3 Differentially expressed miRNAs in the root and shoot of Brassica napus seedlings in response to cadmium stress. a The number of miRNAs up- or down-regulated by $\mathrm{Cd}$ treatment by $>2$-fold in the root and shoot $(P<0.05)$; $\mathbf{b}$ A Venn diagrams showing the unique and shared differentially expressed miRNAs in the root and shoot under Cd stress; c Hierarchical cluster analysis of differentially expressed miRNAs in the root and shoot. CS1, CS2, CS3 indicate control samples for the shoot, TS1, TS2 and TS3 indicate treatment samples for the shoot, CR1, CR2 and CR3 indicate control samples for the root and TR1, TR2 and TR3 indicate treatment samples for the root. The fold-change ratios of the miRNAs are indicated by different colors

expressed mRNAs were down-regulated after Cd treatment in both root and shoot tissues.

\section{Gene ontology (GO) and pathway enrichment revealed the predominance of secondary metabolism, metal ion transport, and antioxidants during the cd response in oilseed rape}

In the root, 67, 38 and nine GO terms were significantly enriched for biological processes, molecular function and cellular component annotations (Additional file 1: Table S5). In the shoot, 52, 33 and four GO terms were significantly enriched for biological processes, molecular function and cellular component annotations (Additional file 1: Table S5).
Biological processes related to secondary metabolic processes were predominantly enriched in both root and shoot tissues, while processes related to transition metal ion transport and camalexin biosynthesis were especially predominant in the root, and processes related to glucosinolate and indoleacetic acid biosynthesis were especially predominant in the shoot (Additional file 1: Table S5). Molecular functions related to superoxide dismutase were especially predominant in the root, while molecular functions related to transcription factors were especially predominant in the shoot (Additional file 1: Table S5). Cellular components of cell wall and extracellular regions were 
Table 1 Significantly differentially expressed miRNA families and miRNAs $(P<0.05)$ in tissues of root and shoot of Brassica napus seedlings under Cd stress

\begin{tabular}{|c|c|c|c|c|c|c|c|c|}
\hline \multirow[t]{2}{*}{ Name } & \multicolumn{4}{|l|}{ Root } & \multicolumn{4}{|l|}{ Shoot } \\
\hline & miRNA num. & Up & Down & Mean $\left[\log _{2}(\right.$ Ratio) $]$ & miRNA num. & Up & Down & Mean $\left[\log _{2}\right.$ (Ratio)] \\
\hline MIR395 family & 2 & 2 & 0 & 2.51 & 2 & 2 & 0 & 2.38 \\
\hline MIR397 family & 1 & 1 & 0 & 2.85 & 1 & 1 & 0 & 3.84 \\
\hline MIR398 family & 2 & 2 & 0 & 2.68 & 2 & 2 & 0 & 1.07 \\
\hline MIR408 family & 1 & 1 & 0 & 3.76 & 1 & 1 & 0 & 2.03 \\
\hline MIR858 family & 1 & 0 & 1 & 1.3 & 1 & 1 & 0 & 1.8 \\
\hline novel_miR_121 & 1 & 1 & 0 & 0.61 & 1 & 0 & 1 & 0.7 \\
\hline novel_miR_164 & 1 & 1 & 0 & 3.29 & 1 & 1 & 0 & 3.52 \\
\hline novel_miR_178 & 1 & 1 & 0 & 3.37 & 1 & 1 & 0 & 2.3 \\
\hline MIR158 family & 1 & 0 & 1 & 0.85 & - & - & - & - \\
\hline MIR169_2 family & 1 & 0 & 1 & 1.92 & - & - & - & - \\
\hline MIR827_2 family & 1 & 0 & 1 & 0.96 & - & - & - & - \\
\hline MIR845_1 family & 1 & 1 & 0 & 0.66 & - & - & - & - \\
\hline MIR860 family & 1 & 0 & 1 & 1.45 & - & - & - & - \\
\hline MIR1511 family & 1 & 0 & 1 & 1.21 & - & - & - & - \\
\hline novel_miR_160 & 1 & 0 & 1 & 2.35 & - & - & - & - \\
\hline novel_miR_19 & 1 & 0 & 1 & 1.07 & - & - & - & - \\
\hline novel_miR_4 & 1 & 0 & 1 & 1.02 & - & - & - & - \\
\hline novel_miR_71 & 1 & 0 & 1 & 1.49 & - & - & - & - \\
\hline novel_miR_78 & 1 & 1 & 0 & 3.86 & - & - & - & - \\
\hline novel_miR_83 & 1 & 0 & 1 & 1.97 & - & - & - & - \\
\hline MIR166 family & - & - & - & - & 2 & 2 & 0 & 1.07 \\
\hline MIR172 family & - & - & - & - & 3 & 0 & 3 & 0.77 \\
\hline MIR319 family & - & - & - & - & 2 & 1 & 1 & 1.11 \\
\hline MIR390 family & - & - & - & - & 1 & 1 & 0 & 1.07 \\
\hline MIR391 family & - & - & - & - & 1 & 0 & 1 & 0.72 \\
\hline MIR396 family & - & - & - & - & 1 & 0 & 1 & 0.92 \\
\hline MIR399 family & - & - & - & - & 1 & 1 & 0 & 0.63 \\
\hline MIR1140 family & - & - & - & - & 1 & 1 & 0 & 0.59 \\
\hline MIR2111 family & - & - & - & - & 1 & 1 & 0 & 2.1 \\
\hline bna-miR6029 & - & - & - & - & 1 & 0 & 1 & 0.69 \\
\hline bna-miR6034 & - & - & - & - & 1 & 1 & 0 & 1.15 \\
\hline novel_miR_103 & - & - & - & - & 1 & 0 & 1 & 0.77 \\
\hline novel_miR_159 & - & - & - & - & 1 & 0 & 1 & 0.6 \\
\hline novel_miR_167 & - & - & - & - & 1 & 0 & 1 & 0.74 \\
\hline novel_miR_38 & - & - & - & - & 1 & 1 & 0 & 2.01 \\
\hline Total & 22 & 11 & 11 & - & 29 & 18 & 11 & - \\
\hline
\end{tabular}

predominantly enriched in both root and shoot tissues (Additional file 1: Table S5).

Pathway enrichment analysis revealed a few important pathways that were significantly enriched in response to $\mathrm{Cd}$ stress (Fig. 5). Pathways related to secondary metabolism processes, such as phenylalanine metabolism and in particular phenylpropanoid biosynthesis were the most significantly enriched pathways in the root tissue (Fig. 5). Pathways involved in amino acid biosynthesis, starch and sucrose metabolism, and other similar secondary metabolism pathways, such as the 2-oxocarboxylic acid metabolism, phenylalanine metabolism, phenylpropanoid biosynthesis 


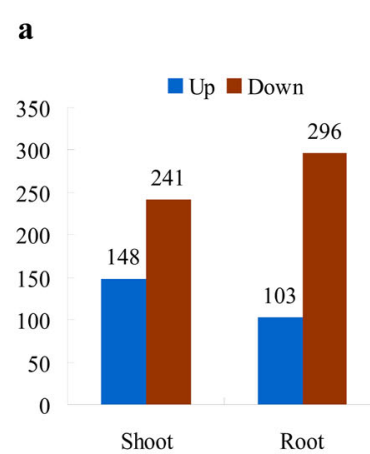

c

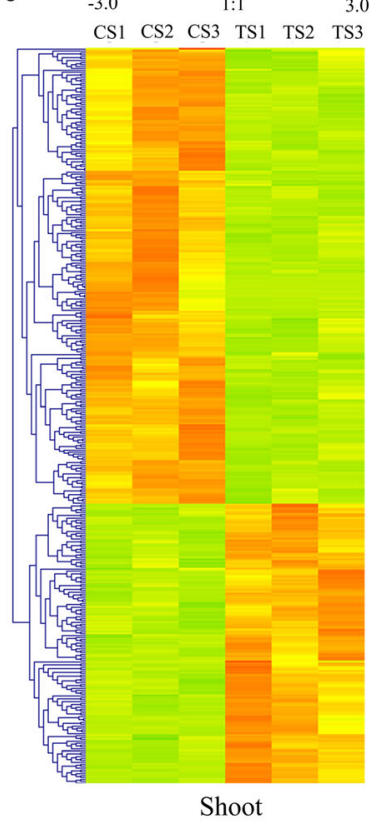

$\begin{array}{lll}-3.0 & 1.1 & 3.0\end{array}$

CR1 CR2 CR3 TR1 TR2 TR3

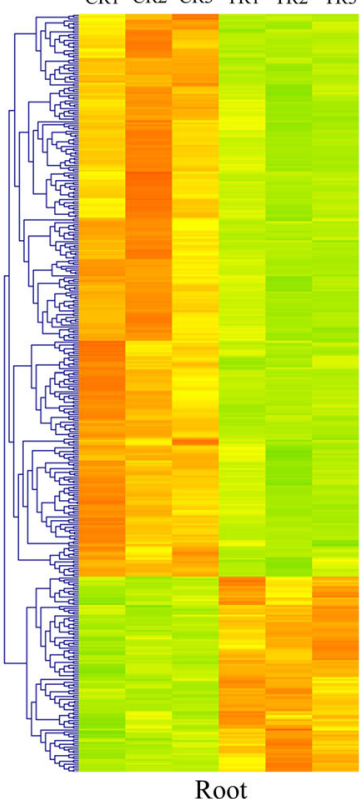

Fig. 4 Differentially expressed genes in the root and shoot of Brassica napus seedlings in response to cadmium stress. a The number of genes up- or down-regulated by $\mathrm{Cd}$ treatment by $>2$-fold in root and shoot $(P<0.05)$; $\mathbf{b}$ A Venn diagrams showing the unique and shared differentially expressed genes in the root and shoot under Cd stress; c Hierarchical cluster analysis of differentially expressed genes in the root and shoot. CS1, CS2, CS3 indicate control samples for the shoot, TS1, TS2 and TS3 indicate treatment samples for the shoot, CR1, CR2 and CR3 indicate control samples for the root and TR1, TR2 and TR3 indicate treatment samples for the root. The fold-change ratios of the genes are indicated by different colors

were the most significantly enriched pathways in the shoot tissue.

\section{DEGs related to key biological processes DEGs involved in cd transport}

Metal transporters have been revealed to mediate heavy metal uptake and translocation in plants [36]. In the present study, 18 and 12 known heavy metal transporters were identified in the root and shoot, including one ZIP (ZRT/IRT-like Proteins), three YSL (yellow Stripe 1-like transporters), four PPase (pyrophosphatase), six NRT (nitrate transporters), two COPT (copper transport protein family), three CML (calcium-binding proteins), two CAM (calmodulin), five ABC (ATP Binding Cassette) transporters, one CAX (vacuolar cation/proton exchanger), and one ATP synthase gene (Table 2, Additional file 1: Table S6). DEGs encoding YSL, PPase, NRT, and ABC transporters were common to both the root and shoot, while DEGs encoding ZIP, COPT, CML and CAM were specific to the root, and DEGs encoding CAX and ATP synthase were specific to the shoot. All genes encoding ZIPs, YSL, COPT, CAM, ABC transporters, and CAX tended to be up-regulated, while all genes encoding PPase, NRT, and ATP synthase were down-regulated.

\section{DEGs involved in regulation of transcription}

Of the 780 genes differentially expressed in the root and shoot of oilseed rape seedlings in response to $\mathrm{Cd}, 67$ genes $(8.6 \%)$ were involved in transcriptional regulation (Additional file 1: Table S7). Interestingly, more than twice as many differentially expressed transcription factors (TFs) were found in the shoot (46 DEGs belonging to 18 TF families) than in the root (22 DEGs belonging to seven TF families) (Table 2, Additional file 1: Table S7). Five TF families were differentially expressed in both shoot and root (Additional file 1: Table S7). Of the differentially expressed TFs, more were down-regulated (29 and 16 in root and shoot respectively) than upregulated (17 and six in root and shoot respectively) (Table 2, Additional file 1: Table S7).

\section{DEGs involved in secondary metabolic processes}

A total of 53 DEGs in the root and 58 DEGs in the shoot were found to be involved in secondary metabolic processes (Table 2, Additional file 1: Table S8). These were involved in eight secondary metabolic pathways: glucosinolate biosynthesis and catabolism, lignin biosynthesis and catabolism, phenylpropanoid metabolism, toxin catabolism, unsaturated fatty acid biosynthesis, flavonoid/ flavonol/anthocyanin biosynthesis, and coumarin biosynthesis. DEGs involved in lignin biosynthesis and cutin 


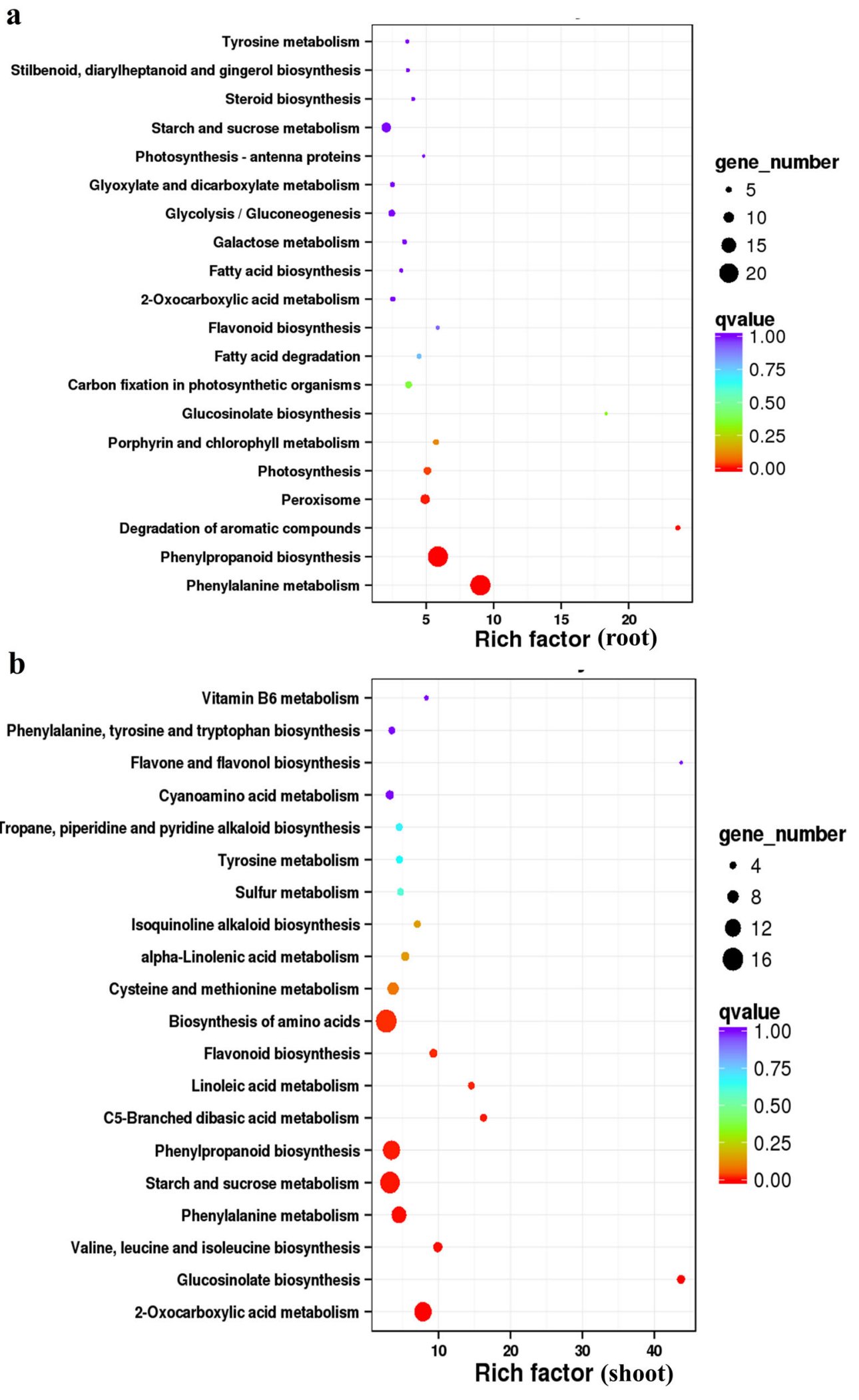

Fig. 5 (See legend on next page.) 
(See figure on previous page.)

Fig. 5 Kyoto Encyclopedia of Genes and Genomes (KEGG) enrichment analysis of differentially expressed genes (DEGs) in the root and shoot of Brassica napus seedlings in response to cadmium stress. a and $\mathbf{b}$ represented the top 20 enriched pathways in the root and shoot, respectively. Each circle represents a KEGG pathway, the $Y$-axis represents the pathway name, and the $X$-axis represents the enrichment factor, which compares the ratio of genes annotated to a pathway among the DEGs to the ratio of genes annotated to that pathway among all genes. The larger the enrichment factor, the more significant the enrichment of DEGs in the pathway

biosynthesis were especially prominent in the shoot and root, respectively (Table 2). The highest numbers of DEGs involved in secondary metabolism processes were related to glucosinolates in both the root (17 DEGs; 14 involved in biosynthesis and three involved in catabolism) and shoot (37 DEGs; 36 involved in biosynthesis and one in catabolism) (Table 2). All 14 DEGs in the root and 33/36 of the DEGs in the shoot involved in glucosinolate biosynthesis were down-regulated (Table 2). Similarly, DEGs related to lignin biosynthesis, phenylpropanoid metabolism, toxin catabolism, and coumarin biosynthesis also showed a trend of down-regulation in both root and shoot (Table 2). By contrast, DEGs related to lignan biosynthesis, unsaturated fatty acid biosynthesis and flavonoid/flavonol/anthocyanin biosynthesis tended to be down-regulated in the root, but upregulated in the shoot (Table 2).

\section{DEGs involved in antioxidant response}

A total of 58 DEGs in the root and 46 DEGs in the shoot encoded different antioxidant families (Table 2, Additional file 1: Table S9). Half of the DEGs (52\%) in the shoot were up-regulated, while most DEGs (85\%) in the root were down-regulated. The antioxidant families peroxidase (POD), 2-oxoglutarate (2-OG) dioxygenase, laccase, and monooxygenase $(\mathrm{MO})$ were induced in both the root and shoot, but the expression trend was opposite between the two tissues, with most DEGs down-regulated in the root but up-regulated in the shoot. Many of the antioxidant families were specific between tissues for $\mathrm{Cd}$ response, such as the copper/zinc superoxide dismutase (SOD), FeSOD, ferretin, $\mathrm{NAD}(\mathrm{P})$-binding Rossmann-fold protein, and zinc-binding dehydrogenase (ZBDH) families, which were specifically induced in the root, and the lipoxygenase, copper amine oxidase $(\mathrm{CuAO})$, ferredoxin:NADP $(\mathrm{H})$ oxidoreductase (FNR), and nitrite reductase (NIR) families which were specifically induced in the shoot. These findings suggested that antioxidant-encoding genes may play important roles in reducing $\mathrm{Cd}$ toxicity in both root and shoot in B. napus, but that the mechanism of protection may be distinct between tissues.

\section{DEGs involved in photosynthesis}

We identified 25 DEGs related to photosynthesis. All of these DEGs were down-regulated in response to $\mathrm{Cd}$ treatment (Table 2, Additional file 1: Table S10). These genes were mainly involved in photosystem subunitrelated processes, chlorophyll-protein complex subunit encoding, rubisco small subunit encoding, electron transport, carbon reduction, and other photosynthesis processes.

\section{A close crosstalk was observed between several cd induced miRNAs and mRNAs}

miRNA-mRNA interaction pair means the anti-regulation of a miRNA and a corresponding mRNA. A total of eight anti-regulation miRNA-mRNA interaction pairs, involving three miRNA families and six target mRNAs, were identified in the root (Table 3, Additional file 1: Table S11). This included seven pairs with up-regulated miRNAs and down-regulated mRNAs, and only one pair with downregulated miRNA and up-regulated mRNA (Table 3, Additional file 1: Table S11). Of the targets, one downregulated target of miR395 comprised an ABA-binding protein encoding magnesium chelatase, which is involved in plastid-to-nucleus signal transduction and is related to chlorophyll biosynthetic process and photosynthesis. The four targets of miR398, two encoding chloroplastic copper/zinc superoxide dismutase 2 (CSD2), one encoding cytosolic copper/zinc superoxide dismutase (CSD1), and one encoding copper-zinc superoxide dismutase copper chaperone (CCS), were also down-regulated,. Thus, the

Table 2 Differentially expressed genes related to cadmium (Cd) transport, transcriptional regulation, and secondary metabolism in roots and shoots of oilseed rape seedlings in response to $\mathrm{Cd}$ treatment

\begin{tabular}{|c|c|c|c|c|c|c|}
\hline \multirow[t]{2}{*}{ Types } & \multicolumn{3}{|l|}{ root } & \multicolumn{3}{|c|}{ shoot } \\
\hline & total & up & down & total & up & down \\
\hline Cd transport & 18 & 11 & 7 & 12 & 7 & 5 \\
\hline Transcription regulation & 22 & 6 & 16 & 46 & 17 & 29 \\
\hline Secondary metabolism & 53 & 6 & 47 & 58 & 17 & 41 \\
\hline Antioxidant response & 58 & 9 & 49 & 46 & 24 & 22 \\
\hline Chlorophyll synthesis and photosynthesis & 16 & 0 & 16 & 9 & 0 & 9 \\
\hline
\end{tabular}




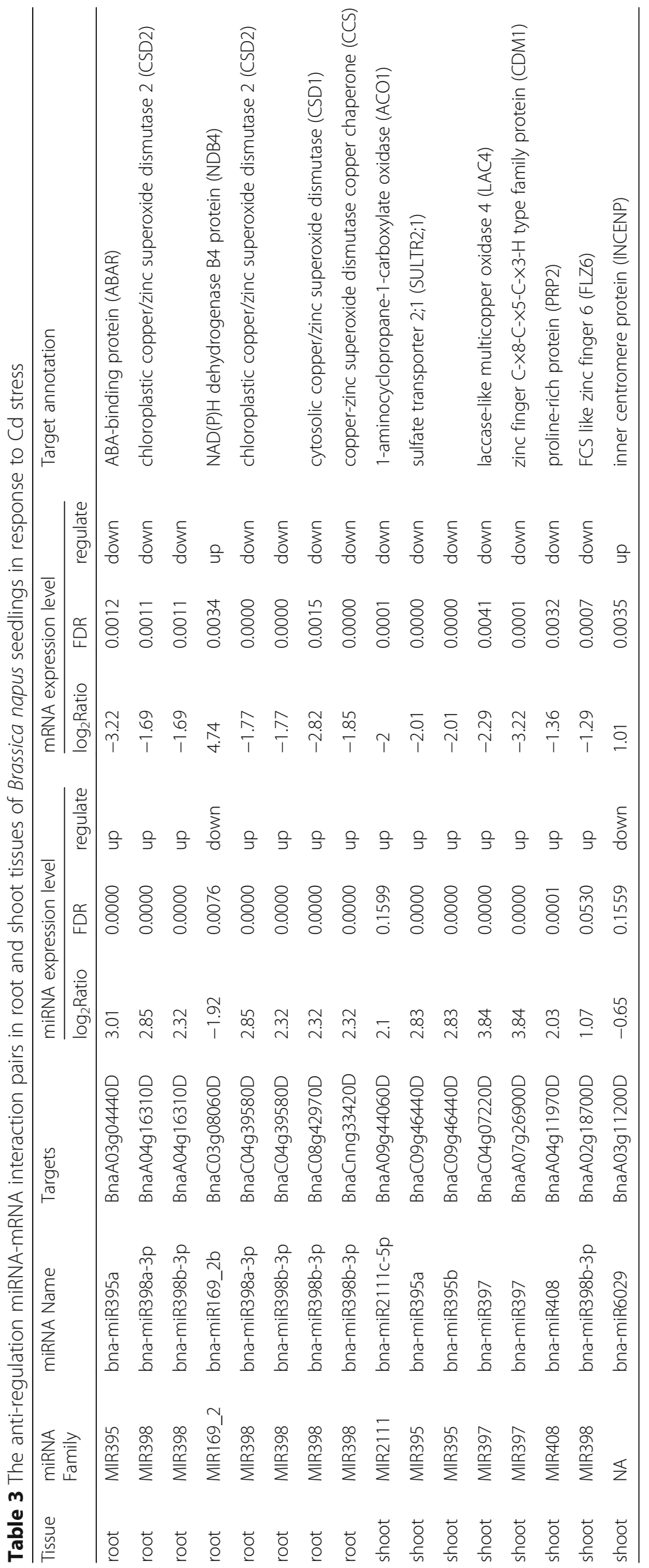


four targets of miR398 were highly correlated and all were involved in the CCS-dependent detoxification of superoxide radicals pathway, which is regulated.

by biotic and abiotic stress. In the shoot, eight antiregulation miRNA-mRNA interaction pairs, involving five miRNA families, one novel miRNA, and seven target mRNAs, were identified (Table 3). Of these, seven pairs were up-regulated miRNAs and down-regulated mRNAs, only one pair displayed down-regulated miRNA and up-regulated mRNA (Table 3). The seven target mRNAs were mainly involved in oxidation-reduction processes and plant organ development.

\section{The expression profile data was validated by real-time RT-PCR}

To validate the expression data, the relative expression levels of 15 randomly selected differentially expressed mRNAs and ten miRNAs from our sequencing data were investigated with qRT-PCR. Our results showed that the qRT-PCR analysis for 13 of the 15 differentially expressed mRNAs and seven of the ten differentially expressed miRNAs displayed similar expression patterns to those generated from high-throughput sequencing (Additional file 2: Figure S1), thus confirming the reliability of the data provided by RNA-Seq.

\section{Discussion}

\section{miRNA regulation of genes in response to cd stress in} oilseed rape

Co-analysis of the expression of miRNA and their putative mRNA targets in response to $\mathrm{Cd}$ stress revealed 7/8 anti-regulation pairs in the root (three miRNA families targeting six mRNAs) and 7/8 anti-regulation pairs in the shoot (five miRNA families targeting seven mRNAs) where miRNA up-regulation was coupled with downregulation of the mRNA, with the remaining two pairs showing miRNA down-regulation coupled with mRNA up-regulation. Several of these targeted genes were involved in processes expected to be initiated in response to $\mathrm{Cd}$ stress. In the shoot, four related genes (an A4 and a C4 copy of CSD2, a CSD1 and a CCS gene) targeted by a single miRNA, belong to the copper/zinc superoxide dismutase genes, which were involved in the CCSdependent detoxification of superoxide radicals pathway, and were regulated by biotic and abiotic stress [37, 38], while another gene in the root was also involved in oxidation-reduction processes and defense response (an ACO1 gene homolog). Other genes were putatively involved in chlorophyll biosynthesis/photosynthesis pathways, sulfate transport, cell wall biosynthesis and organization, cell growth and transcriptional regulation, similar to the categories which we also found to be enriched for differentially expressed genes in response to $\mathrm{Cd}$ stress. Our genome-wide study highlights both
miRNAs and genes which would make excellent targets for detailed experimental investigation of $\mathrm{Cd}$ response in oilseed rape in future.

\section{The expression of a range of miRNAs were changed under cd stress in oilseed rape}

Zhou et al. (2012) previously identified eight miRNA families differentially expressed in response to $\mathrm{Cd}$ stress in $B$. napus roots, and 13 miRNA families differentially expressed in response to Cd stress in B. napus shoots [35]. In the present study, a total of 11 and 14 miRNA families were identified to be responsive to $\mathrm{Cd}$ stress in roots and shoots, respectively (Table 1). As expected, several of the Cd-responsive miRNAs previously identified by Zhou et al. (2012) also showed differential regulation under $\mathrm{Cd}$ stress in our study [35]. For instance, miR319, miR395, miR398, and miR2111, were up-regulated under Cd stress, miR158 and miR172 were down-regulated, whereas miR585 were down-regulated in root and up-regulated in shoot. However, the miR161, miR164, miR171, miR319, miR394, miR400, miR857 and miR1885 families detected in Zhou et al. 2012 were not significantly differentially regulated under $\mathrm{Cd}$ stress in our study, while the miR166, miR169, miR390, miR391, miR396, miR397, miR399, miR408, miR818, miR827, miR845, miR858, miR860, miR1140 and miR1511 families detected in our study were not detected by Zhou et al. (2012). These differences might be caused by the B. napus genotype used or by the longer period of our $\mathrm{Cd}$ treatment relative to this study. Thus, further functional studies are needed to validate the precise regulatory roles of these miRNAs in response to Cd in B. napus.

\section{Cd stress significantly influences the photosynthetic pathway in oilseed rape seedlings}

$\mathrm{Cd}$ can influence photosynthetic pigments, causing a decrease in chlorophyll content and thus affecting photosynthetic function [39, 40]. In our study, the total chlorophyll content showed a very significant decrease five days after treatment under $5 \mathrm{mg} / \mathrm{L}, 10$ $\mathrm{mg} / \mathrm{L}$ and $20 \mathrm{mg} / \mathrm{L} \mathrm{Cd}^{2+}$ (Fig. 1b), and the minimum chlorophyll content occurred after 10 days of treatment when compared with the control. The decrease in chlorophyll content in our study was similar to that observed by Ali et al. (2013b) [41] and Ding et al. (2018) [25], who showed that chlorophyll content significantly decreased with increasing $\mathrm{Cd}$ treatment. We found that the chlorophyll decrease occurred only for younger leaves, but did not decrease the chlorophyll content of older leaf (Fig. 1a). However, unlike the results reported by Ali et al. (2013b) [41], which showed that chlorophyll content significantly decreased as $\mathrm{Cd}$ concentration increased $(0,100$, and $500 \mu \mathrm{M})$, we found that higher $\mathrm{Cd}$ 
concentration arrested the development of younger leaves, causing stability and even a gradual increase in chlorophyll content in older leaves after a long time in high $\mathrm{Cd}$ concentration treatment.

Chloroplast proteins play important roles in chloroplast biogenesis [42]. Defects in chloroplast proteins such as chloroplast protein import subunit (toc36), ATP synthase subunit (atpD), cytochrome b6-f complex iron-sulfur subunit and chloroplast mRNA maturation enzyme, could cause the chlorophyll-deficient phenotype [43]. In the present study, the expression of several chloroplast proteins, including two rubisco small subunit encoding genes, one rubisco activase gene, and three $\mathrm{NAD}(\mathrm{P}) \mathrm{H}$ dehydrogenase genes, was significantly down-regulated in the shoot tissue of $B$. napus under $\mathrm{Cd}$ stress (Additional file 1: Table S10). Izumi et al. (2012) determined that the mutation of two rubisco small subunits yielded a pale green leaf colour in Arabidopsis thaliana [44]. Suorsa et al. (2009) reported that the NDHdeficient plants do not show any phenotype related to greening, but affect cyclic electron transfer around photosystem (PS) I during the photosynthesis process [45]. Thus, it is not surprising that two rubisco small subunit encoding genes and one rubisco activase gene were significantly downregulated under $\mathrm{Cd}$ stress; this might be closely related to the chlorophyll-deficiency phenotype, and linked to the down-regulation of several photosynthesis-related genes.

Although roots do not make chlorophyll or photosynthesise, 16 genes involved in plant chlorophyll synthesis or in the photosynthetic process were identified in response to $\mathrm{Cd}$ in the root. Thus, despite the gene annotation predictions, these genes must have functions other than photosynthesis. For instance, it has been reported that the overexpression of light-dependent protochlorophyllide oxidoreductase PORA or PORB provides protection against photooxidative damage by overexpression of light-dependent protochlorophyllide oxidoreductase PORA or PORB [46]. As well, the magnesium-chelatase $\mathrm{H}$ subunit functions in abscisic acid signaling to regulate plant adaptation to environmental stress challenges, by regulating stomatal aperture and expression of stressresponsive genes [47]. The pyridine nucleotidedisulphide oxidoreductases motifs are highly conserved in the deduced amino acid with sequences from glutathione reductase, which plays an essential role in cell defense against reactive oxygen metabolites [48]. Thus, we speculate that the differential expression of chlorophyll- or photosynthesis-related genes in the roots involves cellular protection mechanisms against the environmental stress caused by $\mathrm{Cd}$.

Glutathione (GSH) metabolism is involved in cd response in both roots and shoots of oilseed rape seedlings

We found that four genes closely co-located downstream of tripeptide glutathione (GSH) were significantly differentially expressed in our study. GSH plays a significant role in stress response [49]. When plants respond to heavy metals, GSH is the substrate for biosynthesis of the heavy metal-binding peptides phytochelatins (PCs), which form metal-thiolate bonds and PC-metal complexes and are then sequestered to the vacuoles [50]. In Arabidopsis thaliana, GSH-deficient mutants with $15-30 \%$ of wild-type levels of GSH show Cd sensitivity [51]. Of the four genes located close together downstream of GSH and significantly differentially expressed in our study (Fig. 6), three were upregulated only in the shoot, suggesting tissue-specific regulation of gene expression. We failed to observe transcriptional regulation of sulfite reductase gene and downstream genes involved in cysteine and GSH biosyntheses in response to $\mathrm{Cd}$ treatment (Fig. 6), despite the fact that most of these genes play a key role in $\mathrm{Cd}$ sensitivity (e.g. gamma-glutamylcysteine synthase (GSH1) [12]. Similar results were also found in Arabidopsis thaliana: although GSH1 enzyme activity increases rapidly in response to $\mathrm{Cd}$ in a dosagedependent manner [52] and glutamylcysteine levels also increase in response to $\mathrm{Cd}$ [53], the expression level of these genes shows no significant change. Our results confirm that sulfite reductase and other downstream genes involved in cysteine and GSH biosynthesis are post-transcriptionally regulated in response to $\mathrm{Cd}$ in $B$. napus, as already demonstrated for other stresses by May et al. (1998a) [54]. Also, in our analyses, genes encoding PC synthases showed no expression change after $\mathrm{Cd}$ treatment (Fig. 6). In previous studies, PC synthases were found to be constitutively expressed and post-transcriptionally regulated by activation of the enzyme in the presence of the metal [15].

Glutathione S-transferase (GST) and glutathione Sconjugate transporters are a group of multifunctional enzymes which catalyze conjugation of GSH with xenobiotic compounds for plant detoxification. In our analysis, two of three DEGs encoding glutathione Stransferase and one glutathione $\mathrm{S}$ - conjugate transporter were up-regulated in the shoot in response to Cd (Fig. 6). Research in yeast cells has found that GST is involved in GSH-Cd formation to decrease Cd uptake [55]. GST also functions as glutathione peroxidase (GPOX) and participates in plant defense against oxidative stress and toxicity generated from heavy metals: Moons et al. (2003) found that $\mathrm{Cd}, \mathrm{Co}, \mathrm{Ni}$ and $\mathrm{Zn}$ significantly enhance the expression of GST genes in rice [56]. Thus, the up-regulation of GST and glutathione S-conjugate transporter in $\mathrm{Cd}$ response in oilseed rape seedlings suggests similar regulatory mechanisms to those in rice, such that the up-regulation of GST is associated with plant $\mathrm{Cd}$ detoxification. 


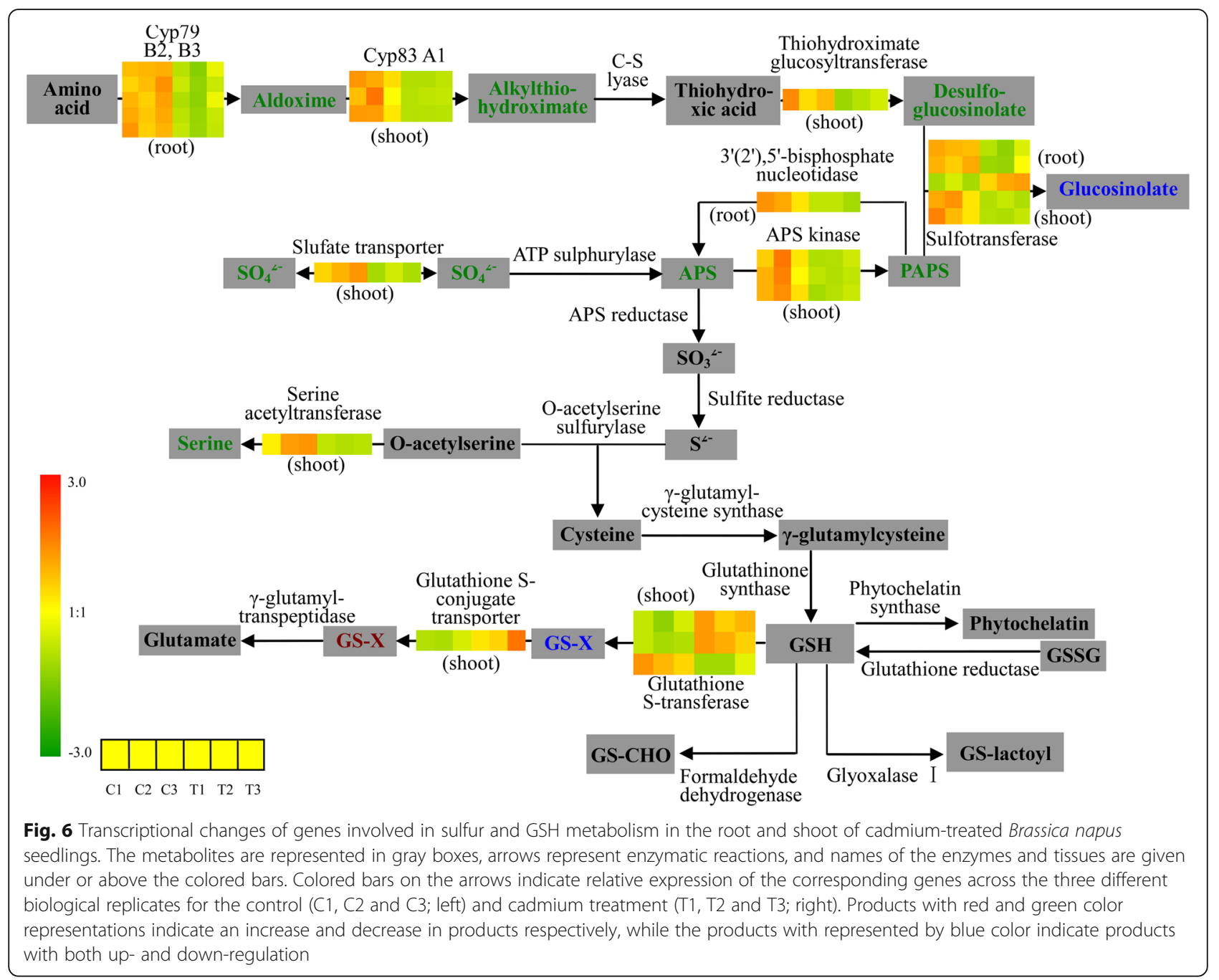

\section{Phenylpropanoid metabolism was involved in cd response in both roots and shoots of oilseed rape seedlings}

$\mathrm{Cd}$ accumulation in plants causes the accumulation of reactive oxygen species (ROS) [57]. ROS can directly damage a wide range of cellular components, such as mitochondria [58], chloroplasts [59], and microtubules [60]. Enhancing ROS-scavenging is an important plant $\mathrm{Cd}$ response mechanism, and phenylpropanoids and their derivatives are well-known ROS scavengers. Several reports have demonstrated that diverse forms of biotic and abiotic stress result in the accumulation of one or more phenolic compounds [61]. In the present study, 12 and 23 DEGs in roots and shoots were directly involved in pathways related to phenylpropanoids and phenylpropanoid derivatives (Fig. 7). In this metabolism pathway, we found all 12 DEGs in the root were down-regulated but that $21 / 23$ DEGs in the shoot were up-regulated, suggesting different regulation of root and shoot tissues. Additionally, most of the DEGs in the shoot were involved in the anthocyanin biosynthesis and modification pathways, but only one gene in these two pathways was found in the roots, suggesting that while the phenylpropanoid-related $\mathrm{Cd}$ response for the shoot was mostly anthocyanin-related, anthocyanins in the root are not involved. These findings in oilseed rape are similar in part to those of Herbette et al. (2006), who demonstrated that genes involved in phenylpropanoid and anthocyanin production are differentially expressed in Arabidopsis thaliana exposed to $\mathrm{Cd}$ treatment [52]. However, Herbette et al. (2006) found upregulated expression of genes involved in phenylpropanoid and anthocyanin production only in leaves of Cd-treated plants, in contrast to our data [52]. This difference may correspond to transitory effects at different time points under Cd stress.

\section{Antioxidant response was a crucial cd-induced response in both roots and shoots of oilseed rape seedlings} The oxidative stress induced by $\mathrm{Cd}$ has been shown to play an important role in plant toxicity [62]. Under 


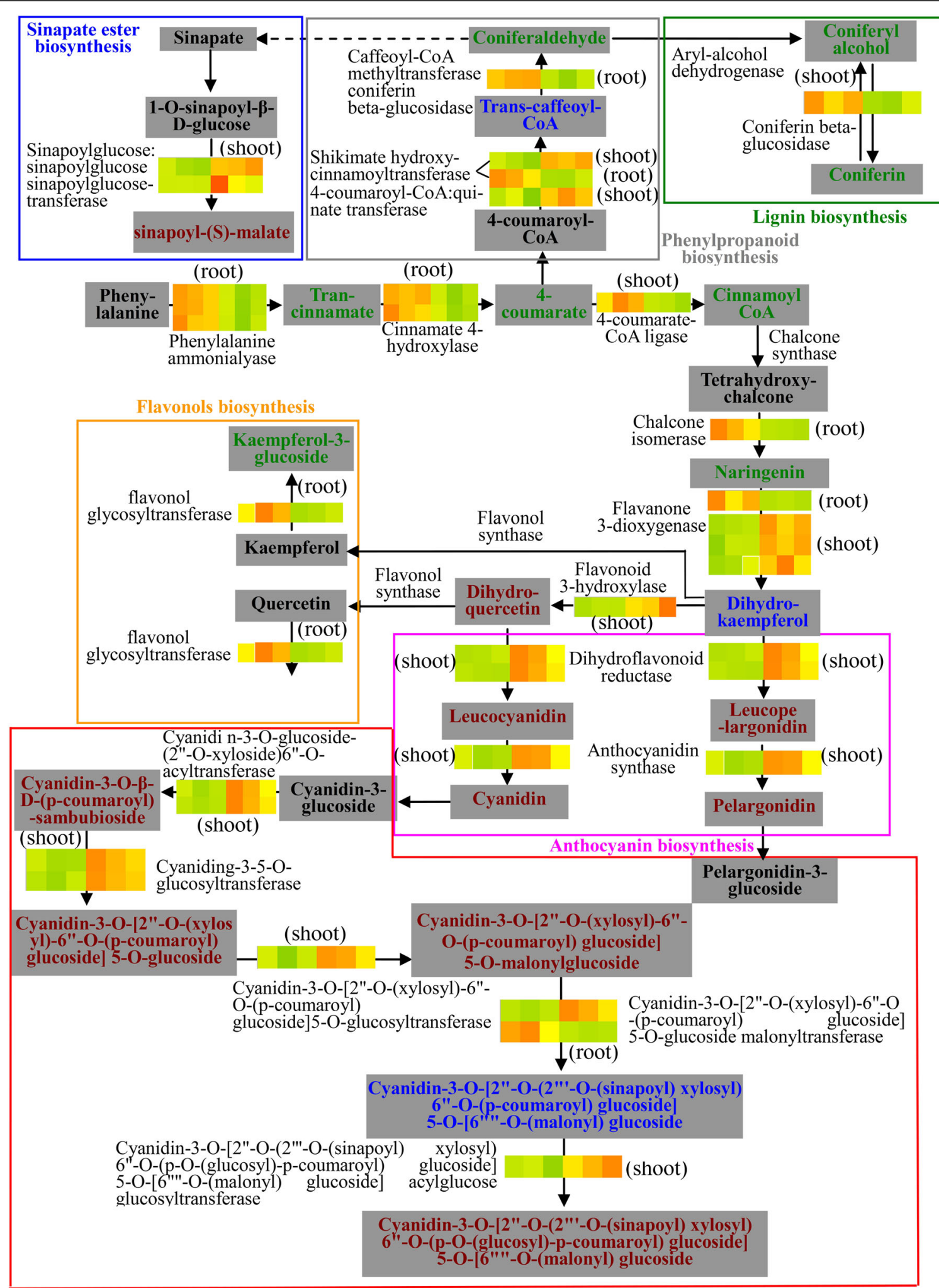

Anthocyanidin modification

Fig. 7 (See legend on next page.) 
(See figure on previous page.)

Fig. 7 Transcriptional changes of genes involved in phenylpropanoid metabolisms in the root and shoot of cadmium-treated Brassica napus seedlings. The metabolites are represented in gray boxes, arrows represent enzymatic reactions, and names of the enzymes and tissue type are given under or above the colored bars. Colored bars on the arrows indicate relative expression of the corresponding genes across the three different biological replicates for the control (C1, C2 and C3; left) and cadmium treatment (T1, $\mathrm{T} 2$ and $\mathrm{T} 3$; right). Products with red and green color representations indicate an increase and decrease in products respectively, while the products with represented by blue color indicate products with both up- and down-regulation

normal conditions, the level of reactive oxygen species (ROS) remains low and does not pose a hazard to plants. However, ROS metabolism is blocked after $\mathrm{Cd}$ stress, and excess ROS, such as superoxide anions, hydroxyl ions, and hydrogen peroxide, accumulate in the cell, cause membrane lipid peroxidation, disrupt the electron transport chain, and lead to oxidative damage in plants [63]. Several studies have found that proline and malondialdehyde content were increased after Cd stress, and that antioxidants such as peroxidase, superoxide dismutase, hydrogen peroxidase, GSH and GST also increased [64], suggesting the stimulation of the antioxidant system. In agreement with the above physiological results, our data found that a set of genes encoding antioxidants such as POD, SOD, Fe-SOD, FNR and lipoxygenase were induced by $\mathrm{Cd}$ stress. However, opposite expression trends and tissue-specific antioxidant families were detected between the tissues of the root and shoot, which suggests that the $\mathrm{Cd}$-induced stress response was distinct between tissues, as also found by Zhou et al. (2012) [28] in B. napus and Herbette et al. (2006) in A. thaliana [52].

\section{TFs play a crucial role in cd response in both roots and shoots of oilseed rape seedlings}

TFs are known to play crucial roles in response to abiotic stresses in plants. In our study, the majority of differentially expressed TFs belonged to the TF families (bHLH) DNA-binding proteins, bZIP, zinc finger, ERF and MYB, and WRKY. In Arabidopsis thaliana and soybean, bHLH transcription factors like bHLH38, bHLH39, bHLH29 and ORG3-Like have been identified to enhance Cd tolerance via decreased cadmium transfer from roots to shoots, and to improve the iron homeostasis and concentration of shoots [65-67]. In Arabidopsis thaliana, the zinc-finger protein AtZAT6 showed significant correlation with $\mathrm{Cd}$ tolerance [65], while the TF families of WRKY, bZIP, ERF, and MYB, are associated with Cd stress in species such as tobacco, maize, walnut and creep bentgrass [68-71]. We also observed several other TF families expressed in response to Cd treatment (Table 2). Briefly, the evidence for direct or indirect roles of TFs in response to $\mathrm{Cd}$ is quite limited. Our study may provide some suggestions regarding the mechanisms of $\mathrm{Cd}$ tolerance at the transcriptional level for future research.

\section{Conclusions}

Cadmium stress induced concurrent expression changes of miRNAs and mRNAs in B. napus seedlings. The shoots and roots showed several differentially expressed miRNAs in common, but there was very little overlap between tissue types for differentially expressed mRNAs in response to $\mathrm{Cd}$. Several anti-regulation miRNAmRNA interaction pairs were identified in response to $\mathrm{Cd}$, and involved key plant stress response pathways such as detoxification of superoxide radicals. The photosynthetic pathway, transcription factor activation, antioxidant response and secondary metabolic processes were identified as major components of response to cadmium in B. napus seedlings. Our results identify key genes and processes for further investigation of $\mathrm{Cd}$ stress responses in B. napus.

\section{Methods}

\section{Plant materials, cd treatment and chlorophyll content measurements}

Seeds of B. napus cultivar 'Zheyou 29' were collected from the Institute of Crop and Nuclear Technology Utilization, Zhejiang Academy of Agricultural Sciences, Hangzhou, China, and used in this study. No other permissions were necessary to collect samples. Seeds of 'Zheyou 29'were surface-sterilized and germinated on Petri dishes with deionized water at $25^{\circ} \mathrm{C}$ for three days in the dark. Germinated seeds were grown in plastic pots in growth chambers under $14 \mathrm{~h}$ light $\left(25^{\circ} \mathrm{C}\right)$ and $10 \mathrm{~h}$ dark $\left(18^{\circ} \mathrm{C}\right)$ conditions for three weeks. Seedlings were transplanted into plastic containers containing half-strength Hoagland nutrient solution for one week. 28-day-old seedlings were exposed to treatment with $\mathrm{CdCl}_{2}$ at six concentrations: $0 \mathrm{mg} / \mathrm{L}$ (control), $5 \mathrm{mg} / \mathrm{L}, 10 \mathrm{mg} / \mathrm{L}, 20 \mathrm{mg} / \mathrm{L}, 30$ $\mathrm{mg} / \mathrm{L}$, and $40 \mathrm{mg} / \mathrm{L}$ of $\mathrm{Cd}^{2+}$. New unfolding leaves were measured for total chlorophyll content according to the methods reported in Yin et al. (2008) [72]. About $0.1 \mathrm{~g}$ of leaf tissue was homogenized in $5 \mathrm{~mL}$ of mixture with acetone: ethanol: water at a 9: 9: $2(\mathrm{v}$ / $\mathrm{v} / \mathrm{v}$ ) ratio, incubated in the dark for $8-12 \mathrm{~h}$, and then centrifuged at $3500 \mathrm{r} / \mathrm{min}$ for $10 \mathrm{~min}$. The 
absorbance of the supernatant was then measured at $652 \mathrm{~nm}$. Eight measurements of chlorophyll content were taken at two-day intervals. Based on these results maximum decreases in chlorophyll content occurred at 10 days post-treatment under $10 \mathrm{mg} / \mathrm{L} \mathrm{Cd}^{2+}$ concentration, so the roots and shoots under this condition were then collected separately for highthroughput sequencing and qRT-PCR. The collected samples were frozen in liquid nitrogen immediately and stored at $-80^{\circ} \mathrm{C}$.

Total RNA was extracted from roots and shoots of oilseed rape seedlings after 10 days of $10 \mathrm{mg} / \mathrm{L} \mathrm{Cd}{ }^{2+}$ treatment and for the control treatment using EZ-10 RNA Miniprep Kits (Sangon Biotech Co., Ltd., Shanghai, China), with three biological replicates for each sample. RNA purity was checked using the NanoPhotometer spectrophotometer (IMPLEN, CA, USA). RNA concentration was measured using a Qubit RNA Assay Kit in a Qubit 2.0 Fluorometer (Life Technologies, CA, USA). RNA integrity was assessed using the RNA Nano 6000 Assay Kit of the Agilent Bioanalyzer 2100 system (Agilent Technologies, CA, USA).

\section{Small RNA and transcriptome sequencing}

A total amount of $2.5 \mathrm{ng}$ RNA per sample was used as input material for the RNA sample preparations. We constructed 12 small RNA sequencing libraries: root control, root treatment under $10 \mathrm{mg} / \mathrm{L} \mathrm{Cd} 2+$ concentration, shoot control, and shoot treatment under $10 \mathrm{mg} / \mathrm{L}$ $\mathrm{Cd} 2+$ concentration, with three biological replicates for

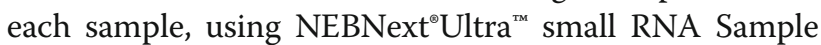
Library Prep Kit for Illumina (NEB, USA) following manufacturer's recommendations. Briefly, total RNA quantity and purity were assayed with an Agilent 2100 Bioanalyzer (Agilent Technologies, Palo Alto, CA) to ensure quality. Then, sRNAs of $18-30 \mathrm{nt}$ were purified from $10 \mu \mathrm{g}$ of total RNA by $15 \%$ polyacrylamide gel electrophoresis. Subsequently, $5^{\prime}$ and 3' RNA adapters were ligated on both ends using T4 RNA ligase. The adapterligated sRNAs were transcribed to cDNA using SuperScript II Reverse Transcriptase and PCR-amplified. Finally, the PCR products were purified and sequenced on an Illumina HiSeq X Ten platform by Biomarker Technologies Co., Ltd. (Beijing, China) and single-end reads were generated.

A total amount of $1 \mu \mathrm{g}$ RNA per sample was used as input material for the RNA sample preparations. 12 transcriptome sequencing libraries: root control, root treatment under $10 \mathrm{mg} / \mathrm{L} \mathrm{Cd} 2+$ concentration, shoot control, shoot treatment under $10 \mathrm{mg} / \mathrm{L} \mathrm{Cd} 2+$ concentration, with three biological replicates for each sample, were generated using NEBNext UltraTM RNA Library Prep Kit for Illumina (NEB, USA) following manufacturer's recommendations. mRNA with
Poly (A) was purified from the total RNA, using oligo(dT) magnetic beads, and then fragmented with an RNA fragmentation kit. First strand cDNA was synthesized using random hexamer primer and M-MuLV Reverse Transcriptase (RNase H-). Second strand cDNA synthesis was subsequently performed using DNA Polymerase I and RNase $\mathrm{H}$. In order to preferentially select cDNA fragments of $200-250 \mathrm{bp}$ in length, the library fragments were purified with AMPure XP system (Beckman Coulter, Beverly, USA). Then, $3 \mu \mathrm{l}$ USER Enzyme (NEB, USA) was used with size-selected, adaptor-ligated cDNA at $37^{\circ} \mathrm{C}$ for 15 min followed by $5 \mathrm{~min}$ at $95^{\circ} \mathrm{C}$ before PCR. Then PCR was performed with Phusion High-Fidelity DNA polymerase, Universal PCR primers and Index (X) Primer. At last, PCR products were purified (AMPure $\mathrm{XP}$ system) and library quality was assessed on the Agilent Bioanalyzer 2100 system. The library preparations were sequenced on an Illumina Hiseq 2500 platform by Biomarker Technologies Co., Ltd. (Beijing, China), for RNA sequencing, and paired-end reads were generated.

\section{Sequencing data analysis}

For small RNA sequencing data, clean reads were firstly obtained by removing contaminants, adaptors, lowquality reads, and reads either shorter than $15 \mathrm{nt}$ or longer than $30 \mathrm{nt}$. The remaining unique RNAs were mapped to the B. napus reference genome (http://www. genoscope.cns.fr/brassicanapus/) using the SOAP2 program [73]. Sequences with a perfect match were retained for further analysis. Using Bowtie tools "soft", the clean reads were aligned respectively with the Silva database (http://www.arb-silva.de/), the GtRNAdb database (http://lowelab.ucsc.edu/GtRNAdb/), the Rfam database (http://rfam.xfam.org/), and the Repbase database (http://www.girinst.org/repbase/) in order to filter out ribosomal RNA (rRNA), transfer RNA (tRNA), small nuclear RNA (snRNA), small nucleolar RNA (snoRNA) and other ncRNA and repeats. The remaining reads were used to detect known miRNA and novel miRNA predicted by comparison to the genome reference and with known miRNAs from miRBase (http://www.mirbase.org/index.shtml). Mireap software (https://sourceforge.net/projects/mireap/) was used for novel miRNA secondary structure prediction. The miRNA expression was normalized using the formula: normalized expression $=$ actual miRNA count/total count of clean reads $\times$ $1,000,000$. The fold change was calculated as: fold change $=\log _{2}$ (Ratio). $|\log 2(\mathrm{FC})| \geq 0.59$ was used to determine the differentially expressed miRNAs. Differential expression analysis was performed using the DESeq $R$ package (1.10.1). DESeq provides statistical routines for determining differential expression in digital miRNA 
expression data using a model based on the negative binomial distribution. The resulting $P$ values were adjusted using the Benjamini and Hochberg's approach for controlling the false discovery rate. Fold change, $P$ values and false discovery rate (FDR) values were used together to screen for differentially expressed miRNAs. The website psRNATarget 2011 (http://plantgrn.noble.org/ psRNATarget/) was used to predict target genes of miRNAs according to default parameters.

For transcriptome data, clean reads were screened from raw data by removing contaminants, adaptors, and low-quality reads. The software "TopHat2" was used to map reads to the reference genome (Brassica napus "Darmor-bzh" v4.1). Gene expression quantification was estimated by fragments per kilobase of transcript per million fragments mapped. The DEGseq (2010) R package was used to analyze the differentially expressed genes (DEGs) with a FDR $<0.001$ and $\mid \log _{2}$ (Ratio) $\mid \geq 1$. The GOseq $\mathrm{R}$ package based on Wallenius non-central hyper-geometric distribution was used to perform the $\mathrm{GO}$ enrichment analysis of the target genes [74]. We used the whole genome as the default background distribution. Resampling was performed by randomly selecting a set of genes the same size as the set of DEGs, and counting the number of genes associated with the GO category of interest. The resampling was repeated many times and the resulting distribution of GO category membership was taken to approximate the shape of the true probability distribution. This sampling distribution allowed calculation of a $P$-value for each GO category being over-represented in the set of differentially expressed genes. $P$-values less than 0.05 and a number of DEGs in each GO category exceeding the expected gene number associated with the GO category were used to identify over-representation of a GO category. DEG enrichment in KEGG pathways was assessed using the software KOBAS [75]. We used the whole genome as the default background distribution. For each pathway that occurred in the set of genes, we counted the total number of genes in the set that were involved in the pathway. We then calculated the $p$-value using a hypergeometric distribution. We performed an FDR correction for multiple testing with default cut-off of 0.05 .

\section{qRT-PCR validation}

We randomly chose 15 differentially-expressed mRNAs and ten miRNAs for quantitative real-time RT-PCR (qRT-PCR) validation. The total RNA extraction procedure was as described above. For mRNA quantification, SuperScript ${ }^{\mathrm{Tm}}$ II Reverse Transcriptase (Invitrogen, USA) and Oligo $(\mathrm{dT})$ primers were used to synthesise firststrand cDNA. Gene-specific primers were designed
(Additional file 1: Table S1). A Bio-Rad CFX96 Realtime System was used for qRT-PCR. Three technical replicates were performed, and the BnActin7 gene was used as a control. SYBR ${ }^{\circ}$ Green PCR Supermix (CA, USA) was chosen for qRT-PCR: the reactions contained $2 \mu \mathrm{L}$ of cDNA, $10 \mu \mathrm{L}$ of SYBR Supermix, $7.2 \mu \mathrm{L}$ of $\mathrm{H}_{2} \mathrm{O}$, and $0.4 \mu \mathrm{L}$ primer $(10 \mu \mathrm{M})$ in a volume of $20 \mu \mathrm{L}$. The reaction program was as follows: $98^{\circ} \mathrm{C}$ for $30 \mathrm{~s}$, followed by 40 cycles of $98^{\circ} \mathrm{C}$ for $10 \mathrm{~s}$ and $60^{\circ} \mathrm{C}$ for $30 \mathrm{~s}$. For mature miRNA quantification, total miRNA was extracted from the serum samples by a miRcute Serum/Plasma miRNA Isolation Kit (TIANGEN, Beijing, China) according to the manual. Single-stranded cDNA was obtained from the extracted miRNA using the One Step Primer Script ${ }^{\circ}$ miRNA cDNA Synthesis Kit (Takara) and SuperScript III Reverse Transcriptase (Invitrogen). qRTPCR with three technical replicates for each reaction was performed to verify the expression of miRNAs through a miDETECT TractTM miRNA qRT-PCR Starter Kit (RiboBio, Guangzhou, China), using U6 snRNA of B. napus as a control. miRNA primers were showed in Additional file 1: Table S1. The $20 \mu \mathrm{l}$ reaction consisting of $2 \mu \mathrm{l} \mathrm{cDNA}, 0.2 \mu \mathrm{M}$ forward and reverse primer, and $10 \mu \mathrm{l}$ of $2 \times$ SYBR Green PCR Master Mix, were carried out on an iCycler iQ real-time PCR detection system (BIO-RAD) with program as follows: $95^{\circ} \mathrm{C}$ for $30 \mathrm{~s}$, and $45 \mathrm{cycles}$ of $95^{\circ} \mathrm{C}$ for $5 \mathrm{~s}, 58^{\circ} \mathrm{C}$ for $15 \mathrm{~s}$, and $72{ }^{\circ} \mathrm{C}$ for $20 \mathrm{~s}$.

\section{Supplementary information}

Supplementary information accompanies this paper at https://doi.org/10. 1186/s12870-019-2189-9.

\footnotetext{
Additional file 1: Table S1. The primer pairs for quantitative real-time RT-PCR (qRT-PCR) validation. Table S2. The statistics of sRNA-seq reads and mapped reads in shoot and root of oilseed rape seedlings under control condition and Cd stress. Table S3. The sequences of newly predicted miRNAs identified in 12 small RNA libraries. Table S4. The statistics of mRNA-seq reads and mapped reads in shoot (S1-S3) and root (R1-R3) tissues of oilseed rape seedlings under control condition (C) and Cd stress ( $T$ ). Table S5. The significantly enriched GO terms during the cadmium response process in root and shoot of $B$. napus. Table S6. The differentially expressed genes related to the process of $C d$ transport in root and shoot of rapeseed seedling response to $\mathrm{Cd}$ treatment. Table S7. The differentially expressed genes related to the process of transcription regulation in root and shoot of rapeseed seedling response to $\mathrm{Cd}$ treatment. Table S8. The differentially expressed genes related to the process of secondary metabolism in root and shoot of rapeseed seedling response to $\mathrm{Cd}$ treatment. Table S9. The differentially expressed genes involved in Cd-induced antioxidant response in root and shoot of rapeseed seedling. Table S10. The differentially expressed genes involved in chlorophyll synthesis and photosynthesis in root and shoot of rapeseed seedling for $\mathrm{Cd}$ response. Table $\mathbf{S 1 1}$. The list of mRNA targets predicted for differentially expressed miRNAs in root and shoot.

Additional file 2: Figure S1. The expression pattern comparison between sequencing data and quantitative RT-PCR data for Brassica napus seedlings exposed to cadmium stress. a The comparison of differentially expressed mRNAs in root with the expression data from quantitative RT-PCR. $\mathbf{b}$ The comparison of differentially expressed miRNAs in root with the expression data from quantitative RT-PCR. $\mathbf{c}$ The comparison of
} 
differentially expressed mRNAs in shoot with the expression data from quantitative RT-PCR. c The comparison of differentially expressed mRNAs in root with the expression data from quantitative RT-PCR. $\mathbf{d}$ The comparison of differentially expressed miRNAs in shoot with the expression data from quantitative RT-PCR.

\section{Abbreviations}

2-OG dioxygenase: 2-oxoglutarate dioxygenase; ABC: ATP Binding Cassette; APS: Adenosine phosphosulfate; CAM: Calmodulin; CAX: Cation/proton exchanger; CCS: Copper-zinc superoxide dismutase copper chaperone; Cd: Cadmium; CML: Calcium-binding proteins; COPT: Copper transport protein; CSD: Copper/zinc superoxide dismutase; CUAO: Copper amine oxidase; DEG: Differentially expressed gene; FDR: False discovery rate; FNR: Ferredoxin:NADP(H) oxidoreductase; GO: Gene ontology; GPOX: Glutathione peroxidase; GSH: Glutathione; GST: Glutathione Stransferase; KEGG: Kyoto Encyclopedia of Genes and Genomes; MiRNAs: MicroRNAs; MO: Monooxygenase; NIR: Nitrite reductase; NRT: Nitrate transporters; PAGE: Polyacrylamide gel electrophoresis; PC: Phytochelatin; POD: Peroxidase; PPase: Pyrophosphatase; RNA: Ribonucleic acid; ROS: Reactive oxygen species; SOD: Superoxide dismutase; TFs: Transcription factors; YSL: Yellow Stripe 1-like transporters; ZBDH: Zinc-binding dehydrogenase; ZIP: ZRT/IRT-like Proteins

\section{Acknowledgements}

Not Applicable.

\section{Authors' contributions}

YF and DF designed the research study; YF, YZ, BL, and HY analyzed data; YF wrote the paper; ASM assisted with interpretation of results, manuscript writing and revision; MX assisted with manuscript revision. All authors read and approved the final manuscript.

\section{Funding}

Y.F. was funded by the Youth Fund of the Natural Science Foundation of Zhejiang Province (LQ19C130002), Y.Z., B.L. and H.Y. were funded by the Project of Mechanized Oilseed rape Breeding of the Downstream of Yangtze River (2018YFD0100602); The Key Project of Novel Variety Breeding of Zhejiang Province (2016C02050-8); The Key Project of Variety Breeding of Seven Major Crops (2016YFD0101306); The Project of Creative Agriculture derived R\&D and Demonstrations of Horticultural Crop Varieties (2018C02057), and M.X. was funded by the National Natural Science Foundation of China (31960411). These funding bodies did not play any roles in the design of the study and collection, analysis, and interpretation of data and in writing the manuscript.

\section{Availability of data and materials}

The datasets generated and analyzed during the current study are presented within the manuscript and supplementary files. All raw sequence reads of both RNA-seq and small RNA-seq have been deposited in NCBI's SRA database (https://trace.ncbi.nlm.nih.gov/Traces/sra/) and are accessible through SRA accession number PRJNA590544 (https://dataview.ncbi.nlm.nih.gov/object/PRJNA590544).

\section{Ethics approval and consent to participate}

Not applicable.

\section{Consent for publication}

Not applicable.

\section{Competing interests}

The authors declare that they have no conflict of interest.

\section{Author details}

'Institute of Crop and Nuclear Technology Utilization, Zhejiang Academy of Agricultural Sciences, Hangzhou, China. ${ }^{2}$ Department of Plant Breeding, IFZ for Biosystems, Land Use and Nutrition, Justus Liebig University, Heinrich-Buff-Ring 26-32, 35392 Giessen, Germany. ${ }^{3}$ Key Laboratory of Crop Physiology, Ecology and Genetic Breeding, Ministry of Education, Agronomy College, Jiangxi Agricultural University, Nanchang 330045, China.
Received: 23 September 2019 Accepted: 8 December 2019

Published online: 19 December 2019

\section{References}

1. Wang $L$, Cui X, Cheng $H$, et al. A review of soil cadmium contamination in China including a health risk assessment. Environ Sci Pollut R. 2015;22: 16441-52.

2. Shamsi IH, Wei K, Zhang GP, Jilani GH, Hassan MJ. Interactive effects of cadmium and aluminum on growth and antioxidative enzymes in soybean. Biol Plantarum. 2008:52:165-9.

3. John MK. Cadmium uptake by eight food crops as influenced by various soil levels of cadmium. Environ Pollut. 1973;4:7-15.

4. Patra M, Bhowmik N, Bandopadhyay B, Sharma A. Comparison of mercury, lead and arsenic with respect to genotoxic effects on plant systems and the development of genetic tolerance. Environ Exp Bot. 2004;52:199-223.

5. DalCorso G, Farinati S, Furini A. Regulatory networks of cadmium stress in plants. Plant Signal Behav. 2010;5:663-7.

6. Montero-Palmero MB, Martin-Barranco A, Escobar C, Hernandez LE. Early transcriptional responses to mercury: a role for ethylene in mercury-induced stress. New Phytol. 2014;201:116-30.

7. Grant CA, Clarke JM, Duguid S, Chaney RL. Selection and breeding of plant cultivars to minimize cadmium accumulation. Sci Total Environ. 2008;390: $301-10$

8. Clemens S, Kim EJ, Neumann D, Schroeder Jl. Tolerance to toxic metals by a gene family of phytochelatin synthases from plants and yeast. EMBO J. 1999:18:3325-33.

9. Gallego SM, Pena LB, Barcia RA, et al. Unravelling cadmium toxicity and tolerance in plants: insight into regulatory mechanisms. Environ Exp Bot. 2012;835:33-46.

10. Hall MJ, Brown MT. Copper and manganese influence the uptake of cadmium in marine macroalgae. B Environ Contam Tox. 2002;68:49-55.

11. Bhaduri AM, Fulekar MH. Antioxidant enzyme responses of plants to heavy metal stress. Rev Environ Sci Bio. 2012;11:55-69.

12. Xiang C, Werner BL, Christensen EM, Oliver DJ. The biological functions of glutathione revisited in Arabidopsis transgenic plants with altered glutathione levels. Plant Physiol. 2001;126:564-74.

13. Grill E, Löffler S, Winnacker EL, Zenk MH. Phytochelatins, the heavy-metalbinding peptides of plants, are synthesized from glutathione by a specific gamma-glutamylcysteine dipeptidyl transpeptidase phytochelatin synthase. P Natl Acad Sci USA. 1989;86:6838-42.

14. Lin YF, Aarts MGM. The molecular mechanism of zinc and cadmium stress response in plants. Cell Mol Life Sci. 2012;69:3187-206.

15. Cobbett C. Pyhtochelatins and their roles in heavy metal detoxification. Plant Physiol. 2000;123:825-32

16. Pence NS, Larsen PB, Ebbs SD, et al. The molecular physiology of heavy metal transport in the $\mathrm{Zn} / \mathrm{cd}$ hyperaccumulator Thlaspi caerulescens. P Natl Acad Sci USA. 2000;97:4956-60

17. Noll M, Lutsenko S. Expression of ZntA, a zinc-transporting P1-type ATPase, is specifically regulated by zinc and cadmium. IUBMB Life. 2000;49:297-302.

18. Shiraishi $\mathrm{E}$, Inouhe $\mathrm{M}$, Joho $\mathrm{M}$, Tohoyama $\mathrm{H}$. The cadmium-resistant gene, $C A D 2$, which is a mutated putative copper-transporter gene PCA1, controls the intracellular cadmium-level in the yeast $S$ cerevisiae. Curr Genet. 2000;37:79-86.

19. Kim DY, Bovet L, Maeshima M, Martinoia E, Lee Y. The ABC transporter AtPDR8 is a cadmium extrusion pump conferring heavy metal resistance. Plant J. 2007:50:207-18.

20. Migocka M, Papierniak A, Rajsz A. Cucumber PDR8/ABCG36 and PDR12/ ABCG40 plasma membrane proteins and their up-regulation under abiotic stresses. Biol Plantarum. 2017;61:115-26.

21. Kim DY, Bovet L, Kushnir S, Noh EW, Martinoia E, Lee Y. AtATM3 is involved in heavy metal resistance in Arabidopsis. Plant Physiol. 2006;140:922-32.

22. Xiao S, Chye ML. Arabidopsis ACBP1 overexpressors are Pbll-tolerant and accumulate Pbll. Plant Signal Behav. 2008;39:693-4.

23. Cao $\mathrm{S}$, Chen Z, Liu G, et al. The Arabidopsis ethylene-insensitive 2 gene is required for lead resistance. Plant Physiol Bioch. 2009;47:308-12.

24. Liu HH, Tian X, Li YJ, Wu CA. Zheng CC microarray-based analysis of stressregulated microRNAs in Arabidopsis thaliana. RNA. 2008;14:836-43.

25. Ding Y, Chen Z, Zhu C. Microarray-based analysis of cadmium-responsive microRNAs in rice Oryza sativa. J Exp Bot. 2011;62:3563-73.

26. Tang MF, Mao DH, Xu LW, et al. Integrated analysis of miRNA and mRNA expression profiles in response to $\mathrm{cd}$ exposure in rice seedlings. BMC Genomics. 2014;15:835. 
27. $\mathrm{Xu} \mathrm{YC,} \mathrm{Chu} \mathrm{LL,} \mathrm{Jin} \mathrm{QJ,} \mathrm{et} \mathrm{al.} \mathrm{Transcriptome-Wide} \mathrm{Identification} \mathrm{of} \mathrm{miRNAs}$ and Their Targets from Typha angustifolia by RNA-Seq and Their Response to Cadmium Stress. PLOS ONE. 2015;10:e0125462.

28. Zhou ZS, Huang SQ, Yang ZM. Bioinformatic identification and expression analysis of new microRNAs from Medicago truncatula. Biochem Bioph Res Co. 2008:374:538-42.

29. Xu L, Wang Y, Zhai LL, et al. Genome-wide identification and characterization of cadmium-responsive micrornas and their target genes in radish (Raphanus sativus I) roots. J Exp Bot. 2013;64:4271-87.

30. Khraiwesh B, Zhu JK, Zhu JH. Role of miRNAs and siRNAs in biotic and abiotic stress responses of plants. BBA-Gene Regul Mech. 1819;2012:137-48.

31. Ebbs SD, Lasat MM, Brady DJ, Cornish J, Gordon R, Kochian LV. Phytoextraction of cadmium and zinc from a contaminated soil. J Environ Qual. 1997;26:1424-30.

32. Clemens S. Developing tools for phytoremediation: towards a molecular understanding of plant metal tolerance and accumulation. Int J Occup Med Env. 2001:14:235-9.

33. Huang $S Q$, Xiang AL, Che LL, et al. A set of miRNAs from Brassica napus in response to sulphate deficiency and cadmium stress. Plant Biotechnol J. 2010;8:887-99.

34. Jian $\mathrm{H}$, Yang $\mathrm{B}$, Zhang $\mathrm{A}$, et al. Genome-wide identification of micrornas in response to cadmium stress in oilseed rape (Brassica napus L) using highthroughput sequencing. Int J Mol Sci. 2018;19:1431.

35. Zhou ZS, Song JB, Yang ZM. Genome-wide identification of Brassica napus microRNAs and their targets in response to cadmium. J Exp Bot. 2012;63: 4597-613.

36. Kramer U, Talke IN, Hanikenn M. Transition metal transport. FEBS Lett. 2007; 581:2263-72.

37. Herouart D, Van Montagu M, Inze D. Redox-activated expression of the cytosolic copper/zinc superoxide dismutase gene in Nicotiana. P Natl Acad Sci USA. 1993;90:3108-12.

38. Chu CC, Lee WC, Guo WY, et al. A copper chaperone for superoxide dismutase that confers three types of copper/zinc superoxide dismutase activity in Arabidopsis. Plant Physiol. 2005;139:425-36.

39. Chandra $R$, Kang $H$. Mixed heavy metal stress on photosynthesis, transpiration rate, and chlorophyll content in poplar hybrids. For Sci. 2016;12:55-61.

40. Hattab S, Dridi B, Chouba L, Ben Kheder M, Bousetta H. Photosynthesis and growth responses of pea Pisum sativum $L$ under heavy metals stress. J Environ Sci. 2009;21:1552-6.

41. Ali B, Wang B, Ali S, et al. 5-aminolevulinic acid ameliorates the growth, photosynthetic gas exchange capacity, and ultrastructural changes under cadmium stress in Brassica napus L. Plant Growth Regul. 2013b; 32:604-14.

42. Motohashi R, Ito T, Kobayashi M, et al. Functional analysis of the $37 \mathrm{kDa}$ inner envelope membrane polypeptide in chloroplast biogenesis using a ds-tagged Arabidopsis pale-green mutant. Plant J. 2003;34:719-31.

43. Budziszewski GJ, Lewis SP, Glover LW, et al. Arabidopsis genes essential for seedling viability: isolation of insertional mutants and molecular cloning. Genet. 2001;159:1765-78.

44. Izumi M, Tsunoda H, Suzuki $Y$, et al. RBCS1A and RBCS3B, two major members within the Arabidopsis RBCS multigene family, function to yield sufficient Rubisco content for leaf photosynthetic capacity. J Exp Bot. 2012; 63:2159-70.

45. Suorsa M, Sirpiö S, Aro EM. Towards characterization of the chloroplast NAD (P) H dehydrogenase complex. Mol Plant. 2009;2(6):1127-40.

46. Sperling U, Van Cleve B, Frick G, Apel K, Armstrong GA. Overexpression of light-dependent pora or porb in plants depleted of endogenous por by farred light enhances seedling survival in white light and protects against photooxidative damage. Plant J. 2010;12:649-58.

47. Wu FQ, Xin Q, Cao Z, et al. The magnesium-chelatase $H$ subunit binds abscisic acid and functions in abscisic acid signaling: new evidence in Arabidopsis. Plant Physiol. 2009;150:1940-54

48. Seo JS, Lee KW, Rhee JS, et al Environmental stressors (salinity, heavy metals, $\mathrm{H}_{2} \mathrm{O}_{2}$ ) modulate expression of glutathione reductase (GR) gene from the intertidal copepod tigriopus japonicus. Aquat Toxicol 2006; 80: 0-289.

49. May MJ, Vernoux T, Leaver C, Van Montague M, Inze D. Glutathione homeostasis in plants: implications for environmental sensing and plant development. J Exp Bot. 1998:49:649-67.

50. Rauser WE. Phytochelatins and related peptides structure, biosynthesis, and function. Plant Physiol. 1995;109:1141-9.
51. Howden R, Andersen CR, Goldsbrough PB, Cobbett CS. A cadmium sensitive, glutathione-deficient mutant of Arabidopsis thaliana. Plant Physiol. 1995; 107:1067-73.

52. Herbette S, Taconnat L, Hugouvieux V, et al. Genome-wide transcriptome profiling of the early cadmium response of Arabidopsis roots and shoots. Biochimie. 2006;88:1751-65.

53. Sarry JE, Kuhn L, Ducruix C, et al. Nramp5 is a major transporter responsible for manganese and cadmium uptake in rice. Plant Cell. 2012;24:2155-67.

54. May M, Vernoux T, Sánchez-Fernández R, Van Montagu M, Inzé D. Evidence for posttranscriptional activation of gamma-glutamylcysteine synthetase during plant stress responses. P Natl Acad Sci USA. 1998a;95: 12049-54.

55. Adamis PDB, Gomes DS, Pinto MLCC, Panek AD, Eleutherio EA. The role of glutathione transferases in cadmium stress. Toxicol Lett. 2004;154:81-8.

56. Moons A. Osgstu3 and osgtu4, encoding tau class glutathione Stransferases, are heavy metal-and hypoxic stress-induced and differentially salt stress-responsive in rice roots 1. FEBS Lett. 2003;553:427-32.

57. Romero-Puertas M, Rodriguez-serrano M, Corpas F, Gomez M, Del Rio L. Cadmium-induced subcellular accumulation of $\mathrm{O}_{2}-$ and $\mathrm{H}_{2} \mathrm{O}_{2}$ in pea leaves. Plant Cell Environ. 2004:27:1122-34

58. Taylor NL, Millar AH. Oxidative stress and plant mitochondria. Methods Mol Biol. 2007;372:389-403.

59. Khanna-Chopra R. Leaf senescence and abiotic stresses share reactive oxygen species-mediated chloroplast degradation. Protoplasma. 2012;249: 469-81.

60. Livanos P, Galatis B, Apostolakos P. The interplay between ROS and tubulin cytoskeleton in plants. Plant Signal Behav. 2014;9:e28069.

61. Ferreres F, Figueiredo R, Bettencourt $S$, et al. Identification of phenolic compounds in isolated vacuoles of the medicinal plant Catharanthus roseus and their interaction with vacuolar class III peroxidase: an $\mathrm{H} 2 \mathrm{O} 2$ affair? J Exp Bot. 2011:62:2841-54.

62. Bernard F, Dumez S, Brulle F, et al. Antioxidant defense gene analysis in Brassica oleracea and Trifolium repens exposed to cd and/or Pb. Environ Sci Pollut R. 2016;23:3136-51.

63. Hasanuzzaman M, Nahar K, Anee TI, Fujita M. Exogenous silicon attenuates cadmium-induced oxidative stress in Brassica napus $L$ by modulating AsA-GSH pathway and glyoxalase system. Front Plant Sci. 2017;8:1061.

64. Iannelli MA, Pietrini F, Fiore $L$, Petrilli $L$, Massacci A. Antioxidant response to cadmium in Phragmites australis plants. Plant Physiol Bioch. 2002;40:977-82.

65. Chen J, Yang L, Yan X, et al. Zinc-finger transcription factor ZAT6 positively regulates cadmium tolerance through the glutathione-dependent pathway in Arabidopsis. Plant Physiol. 2016;171:707-19.

66. Wu H, Chen C, Du J, et al. Co-overexpression FIT with AtbHLH38 or AtbHLH39 in Arabidopsis-enhanced cadmium tolerance via increased cadmium sequestration in roots and improved iron homeostasis of shoots. Plant Physiol. 2012;158:790-800.

67. Xu Z, Liu X, He X, et al. The soybean basic helix-loop-helix transcription factor ORG3-Like enhances cadmium tolerance via increased iron and reduced cadmium uptake and transport from roots to shoots. Front Plant Sci. 2017;8:1098.

68. Guan C, Ji J, Li X, Jin C, Wang G. LCMKK, a MAPK kinase fromLycium chinense, confers cadmium tolerance in transgenic tobacco by transcriptional upregulation of ethylene responsive transcription factor gene. J Genet. 2016;95:875-85

69. Li M, Hao P, Cao F. Glutathione-induced alleviation of cadmium toxicity in Zea mays. Plant Physiol Biochem. 2017;119:240-9.

70. Xu Z, Ge Y, Zhang W, Zhao Y, Yang G. The walnut JrVHAG1 gene is involved in cadmium stress response through ABA-signal pathway and MYB transcription regulation. BMC Plant Biol. 2018;18:19.

71. Yuan J, Bai Y, Chao Y, et al. Genome-wide analysis reveals four key transcription factors associated with cadmium stress in creeping bentgrass (Agrostis stolonifera L). Peerj. 2018;6:e5191.

72. Yin $X L$, Jiang $L$, Song $N H$, Yang $H$. Toxic reactivity of wheat Triticum aestivum plants to herbicide isoproturon. J Agr Food Chem. 2008;56: 48254831

73. Li R, Yu C, Li Y, et al. SOAP2: an improved ultrafast tool for short read alignment. Bioinform. 2009;25:1966-7.

74. Young MD, Wakefield MJ, Smyth GK, Oshlack A. Gene ontology analysis for RNA-seq: accounting for selection bias. Genome Biol. 2010;11:R14. 
75. Mao X, Cai T, Olyarchuk JG, Wei L. Automated genome annotation and pathway identification using the KEGG Orthology KO as a controlled vocabulary. Bioinform. 2005;21:3787-93.

\section{Publisher's Note}

Springer Nature remains neutral with regard to jurisdictional claims in published maps and institutional affiliations.

Ready to submit your research? Choose BMC and benefit from:

- fast, convenient online submission

- thorough peer review by experienced researchers in your field

- rapid publication on acceptance

- support for research data, including large and complex data types

- gold Open Access which fosters wider collaboration and increased citations

- maximum visibility for your research: over $100 \mathrm{M}$ website views per year

At $B M C$, research is always in progress. 